\title{
State of the Art of Bodipy-based Photocatalysts in Organic Synthesis
}

\author{
Paul De Bonfils, ${ }^{[a]}$ Louis Péault, ${ }^{[a]}$ Pierrick Nun, ${ }^{[a]}$ and Vincent Coeffard ${ }^{*[a]}$ \\ [a] P. De Bonfils, L. Péault, Dr. P. Nun, Dr. V. Coeffard \\ CEISAM UMR CNRS 6230, Université de Nantes, F-44000 Nantes, France. \\ E-mail : vincent.coeffard@univ-nantes.fr
}

\begin{abstract}
Photochemistry is a tremendous research field offering many synthetic possibilities to the chemists. Breakthroughs in this area have been notably driven by the implementation of new classes of photocatalysts. Within this context, Bodipy (Borondipyrromethene) dyes possess attractive chemical and physical features such as their modularity, strong absorption under visible light irradiation, good thermal and photochemical stabilities and high fluorescence quantum yields. As such, this class of compounds has found widespread applications in functionalized materials, biology, medicine or organic chemistry. From an organic-synthetic point of view, excited states of Bodipy dyes have been harnessed in electron and energy transfer reactions. This minireview collates the relevant literature on the applications of these catalysts in synthetic photochemistry and provides some perspectives of this research area.
\end{abstract}

Paul de Bonfils was born in Nancy in 1990 He received his M.Sc degree from the Université de Nantes (France) in 2019. Paul is currently working as a Ph.D student in the research group of Dr. Vincent Coeffard. His research focuses on the design of new photosensitizers for application in photodynamic therapy.

Louis Péault was born in Les Sables d'Olonne (France) in 1994. He studied chemistry at École Normale Supérieure Paris-Saclay (France) and he is now following Ph.D studies under the supervision of Dr. Vincent Coeffard on singlet oxygen chemistry.
Pierrick Nun was born in Brest (France) in 1982. After undergraduate studies at Université de Nantes (France), he completed his Ph.D. in 2009 under the supervision of Dr. Frédéric Lamaty at Université de Montpellier (France), working on mechanical activation and solvent-free synthesis. He then joined the group of Prof. Steven P. Nolan at the University of St.

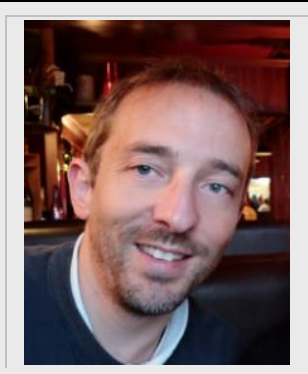
Andrews (Scotland) as a post-doctoral researcher. Following a second post-doctoral fellowship with Prof. Annie-Claude Gaumont at the Ecole Nationale Superieure d'Ingenieurs of Caen (France), he was appointed Assistant Professor at Université de Nantes and he is currently working on singlet oxygen applications in organic synthesis and medicine.

Vincent Coeffard was born in Nantes (France) in 1981. He studied chemistry at Université de Nantes and he completed his Ph.D studies in 2007 in the group of Prof. Jean-Paul Quintard. He then moved to University College Dublin (Ireland) to work as a postdoctoral research fellow for two years in asymmetric catalysis under the guidance of Prof. Pat Guiry. Vincent then spent ten months in Spain for a second postdoctoral experience in the group of Prof

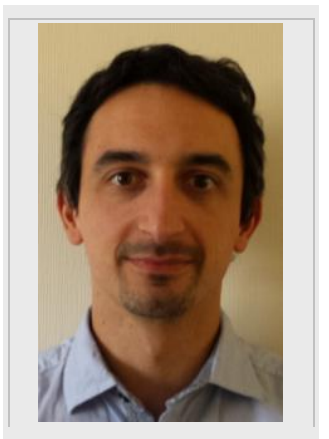
Antonio Echavarren to investigate gold chemistry. In 2010, he was appointed CNRS researcher in the group of Prof. Christine Greck at Université de Versailles Saint-Quentin-en-Yvelines (France) to work on organocatalysis. In 2016, Vincent moved to Université de Nantes where his current research interests include asymmetric organocatalysis, singlet oxygen chemistry and photochemistry.

\section{Introduction}

Organic Chemistry is a discipline which responds to constantly changing synthetic challenges. Amongst the tools available to organic chemists, photocatalysis is a powerful strategy to create and break chemical bonds under smooth conditions. ${ }^{[1]}$ Over the past decades, this field has blossomed into a thriving research area encompassing different tactics to achieve photochemical transformations under visible light irradiation. For instance, photoredox catalysis, ${ }^{[2]}$ energy transfer catalysis ${ }^{[3]}$ and catalytic electron donor-acceptor complexes ${ }^{[4]}$ are key strategies promoting diverse modes of reactivity. Besides the reaction conditions (i.e. temperature, solvent...) and the nature of the reactor device (i.e. classical batch reactor, flow chemistry), a 
critical factor for the success of a photoinduced transformation lies in the careful selection of the photocatalyst. Important criteria for deciding which photocatalyst to select for a given transformation are the photophysical properties, ground state and excited state redox potentials, cost, commercial availability or ease of synthesis of the dye. Within this context, iridium and ruthenium polypyridyl complexes have delivered groundbreaking results in visible light photocatalysis owing to their ability to promote efficiently single electron transfer (SET) and energy transfer (ET) processes. ${ }^{[5]}$ Nevertheless, the high cost of the organometallic complexes and the generation of heavy metal waste have prompted the scientific community to find photocatalysts deprived of transition metals. One approach in which this demand can be achieved is through the use of copper catalysts which represent a low-cost solution to precious metal complexes. ${ }^{[6]}$ In addition, copper containing photocatalysts have interesting features such as tunable excited-state redox potentials and the possibility to promote asymmetric photoredox processes by a careful selection of ligands. ${ }^{[7]}$ Besides copper, iron, ${ }^{[8]}$ chromium ${ }^{[9]}$ or other metal complexes ${ }^{[10]}$ have also been applied in photoredox catalysis. With the aim of developing more sustainable photocatalytic transformations and discovering new reactivities, numerous research groups have also investigated the use of organic photocatalysts in synthetic chemistry. ${ }^{[11]}$ To cite only a few, porphyrinoids, acridinium salts, (thio)xanthene dyes, pyriliums, benzophenones, phenalenones or thiazines are leading organic photocatalysts enabling a large palette of reactions. In addition to these structures, the Bodipy (Borondipyrromethene) dye is an attractive platform for applications in photoorganocatalysis (Figure 1).

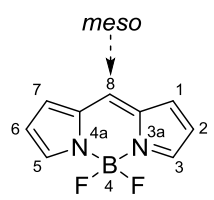

Figure 1. Typical structure and numbering of a Bodipy dye (4,4-Difluoro-4bora-3a,4a-diaza-s-indacene).

This class of compounds offers numerous advantages such as: i) straightforward synthesis and ease of modification via postfunctionalization strategies; ii) high modularity enabling a fine tuning of the photophysical and electrochemical properties; iii) strong absorption under visible light irradiation, iv) high fluorescence quantum yields for some structures and $v$ ) good thermal and photochemical stabilities. ${ }^{[12]}$ The range of $\mathrm{pH}$ and temperature for which the Bodipy framework is stable is suitable for many applications. ${ }^{[13]}$ Interestingly, studies have shown that modulation of the substituents at boron can improve the chemical stability of the Bodipy chromophore. ${ }^{[14]}$ Therefore, Bodipy compounds have been extensively studied as fluorescent molecular probes, ${ }^{[15]}$ photodynamic therapy agents, ${ }^{[16]}$ chromophores in material science ${ }^{[17]}$ and laser dyes. ${ }^{[18]}$ The exploitation of Bodipy dyes has also been extended to organic synthesis with applications ranging from single electron transfer processes to photosensitization. In this review, we will outline the recent advances of Bodipy-based organic photocatalysts in chemical synthesis. After a concise overview of the synthetic routes towards the Bodipy core, the examples selected throughout the review are aimed at demonstrating the effectiveness of Bodipy dyes in photocatalysis. A special attention will be given to photoinduced synthetic methodologies comparing Bodipy dyes with other photocatalysts in order to lend further credence to the assets of these photoorganocatalysts in chemical synthesis.

\section{Synthetic routes towards Bodipy platforms}

The first synthesis of a Bodipy dye dates back from 1968 and this work was reported by Treibs and Kreuzer. ${ }^{[19]}$ Profusion of synthetic procedures that ensued from this discovery relied mainly on the condensation of functionalized pyrroles with a carbonyl compound (aldehyde, acyl chloride, acid anhydride) as a pivotal step. (Scheme 1). ${ }^{[20]}$

1) Reaction of pyrroles with an aldehyde or an acyl chloride

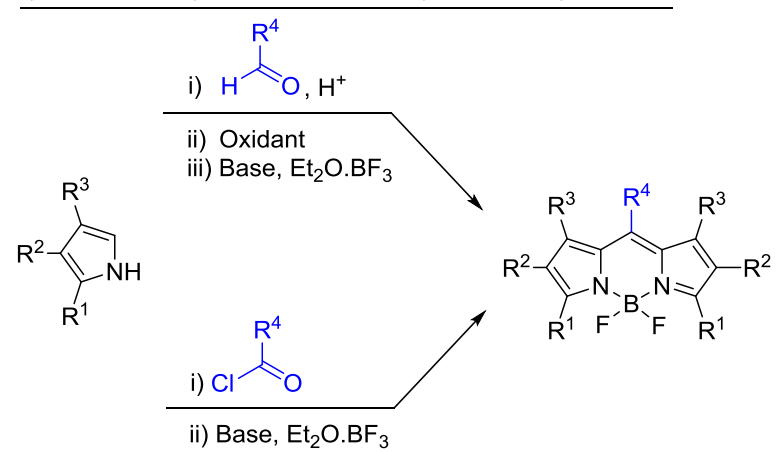

2) Reaction of pyrroles with an acid anhydride

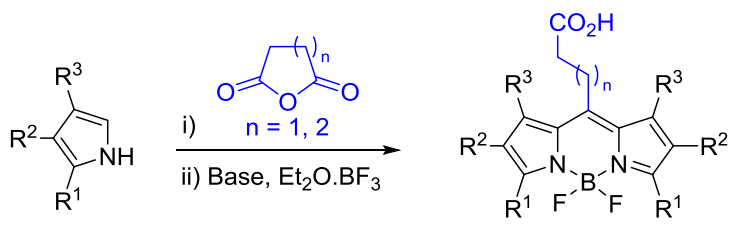

3) Condensation with a carbonyl-containing pyrrole

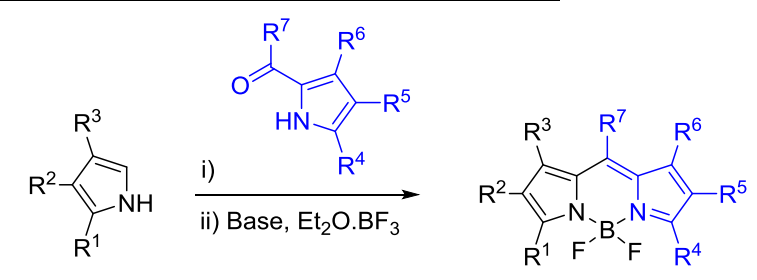

Scheme 1. Synthetic routes towards Bodipy dyes.

One common strategy to prepare functionalized Bodipy dyes lies in the condensation of two pyrrole units with an aldehyde under acidic conditions (i.e. Trifluoroacetic acid, TFA) to form the dipyrromethane framework. Oxidation typically carried out by DDQ (2,3-dichloro-5,6-dicyano-p-benzoquinone) or chloroanil followed by treatment with a base (i.e. $\mathrm{Et}_{3} \mathrm{~N}, \mathrm{~N}, \mathrm{~N}$ Diisopropylethylamine) and $\mathrm{Et}_{2} \mathrm{O}_{\mathrm{BF}} \mathrm{BF}_{3}$ afford the mesosubstituted Bodipy dye (Scheme 1.1). A stepwise tactic or onepot procedures without any purification of the intermediates may be performed for the synthesis of the Bodipy core. An efficient alternative synthetic route involves acyl chlorides as starting materials but their limited commercial availability and stability are potential limitations to reach diversely functionalized Bodipy dyes (Scheme 1.1). Acid anhydrides are also prone to react with pyrroles leading to Bodipy frameworks after complexation 
with $\mathrm{Et}_{2} \mathrm{O}_{\mathrm{BF}} \mathrm{BF}_{3}$ (Scheme 1.2). ${ }^{[1]}$ Under these conditions, the Bodipy dyes are flanked with an alkyl carboxylic side chain allowing further functionalization possibilities. These synthetic strategies turned out to be efficient for reaching symmetric Bodipy compounds while the access to non-symmetric compounds requires alternative routes. To this aim, the condensation of an $\alpha$-free pyrrole with a carbonyl-containing pyrrole followed by treatment with $\mathrm{Et}_{2} \mathrm{O} . \mathrm{BF}_{3}$ has been used to prepare non-symmetric units (Scheme 1.3). ${ }^{[22]}$

One of the reasons for the popularity of Bodipy dyes is related to their ease of functionalization whereas other off-the-shelf organophotocatalysts (i.e. Rose Bengal, Methylene blue) may be less amenable to modification. Numerous postfunctionalization strategies have been successfully reported to modify the properties of the Bodipy dyes. ${ }^{[23]}$ While out of the scope of this review, derivatizations of Bodipy dyes impact on their final applications as exemplified in Scheme 2. ${ }^{[24]}$
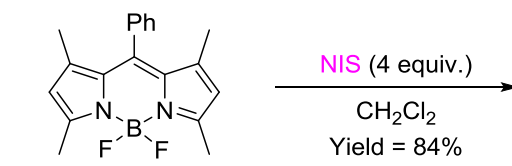

B1

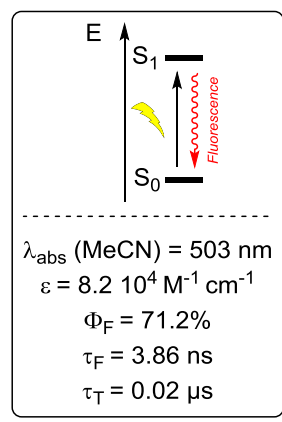

From fluorescent dye (B1) to triplet sensitizer (B2)
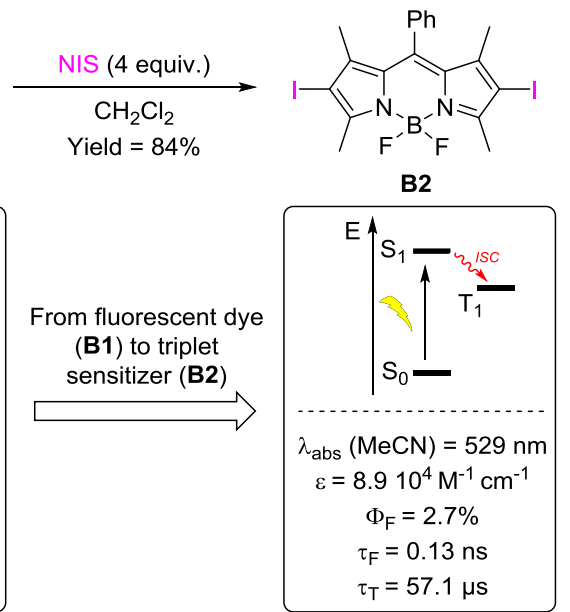

B2

Scheme 2. Heavy atom containing Bodipy dye B2

In this example, the attachment of two iodine atoms to the Bodipy core B1 strongly affects the photophysical properties of the dye. ${ }^{[25]}$ While UV-visible absorption analyses showed a similar behavior for B1 and B2 with intense molar extinction coefficients $(\varepsilon)$, a striking difference of fluorescence quantum yields $\left(\Phi_{\mathrm{F}}\right)$ was observed with a dramatic decrease of the value with iodo substitution. On the other hand, a long-lived triplet excited state was observed for $\mathbf{B 2}$ compared to the parent Bodipy B1 with a lifetime of triplet state $\left(\tau_{\mathrm{T}}\right)$ for $\mathbf{B} 2$ reaching 57.1 $\mu$ s. By comparison, the widely used $\mathrm{Ru}(\mathrm{bpy})_{3} \mathrm{Cl}_{2}$ (bpy $=2,2^{\prime}-$ bipyridine) shows absorption at $450 \mathrm{~nm}$ with a molar extinction coefficient usually less than $20000 \mathrm{M}^{-1} \mathrm{~cm}^{-1}$ and a short triplet lifetime $\left(\tau_{T}=1.1 \mu \mathrm{s}\right) .{ }^{[6]}$ The values compiled in Scheme 2 indicate that the main deactivation pathway of the excited state in $\mathbf{B 1}$ includes fluorescence while it is intersystem crossing to the triplet state for B2. These results are explained by the presence of heavy atoms (iodine atoms) on the $\pi$-core of Bodipy B2 which promote intersystem crossing (ISC) via spin-orbit coupling interactions leading to a long living-triplet excited state. ${ }^{[27]}$ Therefore, a subtle functionalization of the Bodipy core changes the parent fluorescent dye $\mathbf{B} 1$ into an efficient triplet sensitizer $\mathbf{B 2}$ prone to activate molecules by energy transfer or electron transfer processes. Examples highlighting the use of triplet photosensitizers in organic synthesis will be given in the next sections.

\section{Applications of Bodipy in photoorganocatalysis}

\subsection{Formation of $\mathrm{C}-\mathrm{C}$ bonds}

In 2013, the group of Zhao harnessed iodo-Bodipy catalysts B2 and B3 in photoredox organic reactions such as the aerobic cross-dehydrogenative coupling reaction of $\mathrm{N}$-aryl tetrahydroisoquinolines 1 with nitroalkanes 2 (Scheme 3). ${ }^{[28]} \mathrm{A}$ series of photocatalysts was tested in the photoredox reaction and the best results were obtained with the iodo-Bodipy derivatives B2 and B3. The presence of styryl groups on the Bodipy framework strongly impacts the absorption profile and B3 displayed a red-shift absorption $\left(\lambda_{\text {abs }}=630 \mathrm{~nm}\right.$ in $\left.\mathrm{CH}_{2} \mathrm{Cl}_{2}\right)$. The reaction scope was extended to other $\mathrm{N}$-aryl substituted tetrahydroisoquinolines $\mathbf{1}$ and nitroalkanes leading to the desired products 3 in moderate-to-excellent yields. Acetone was also tested as a nucleophile in the presence of $20 \mathrm{~mol} \%$ of L-Proline.

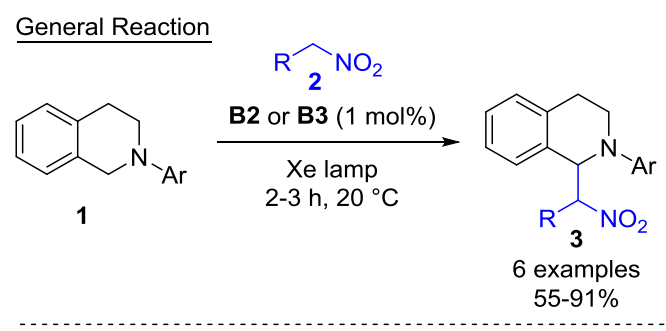

Influence of the photocatalyst (reaction for $\mathrm{Ar}=\mathrm{Ph}, \mathrm{R}=\mathrm{H}, 2 \mathrm{~h}$ )
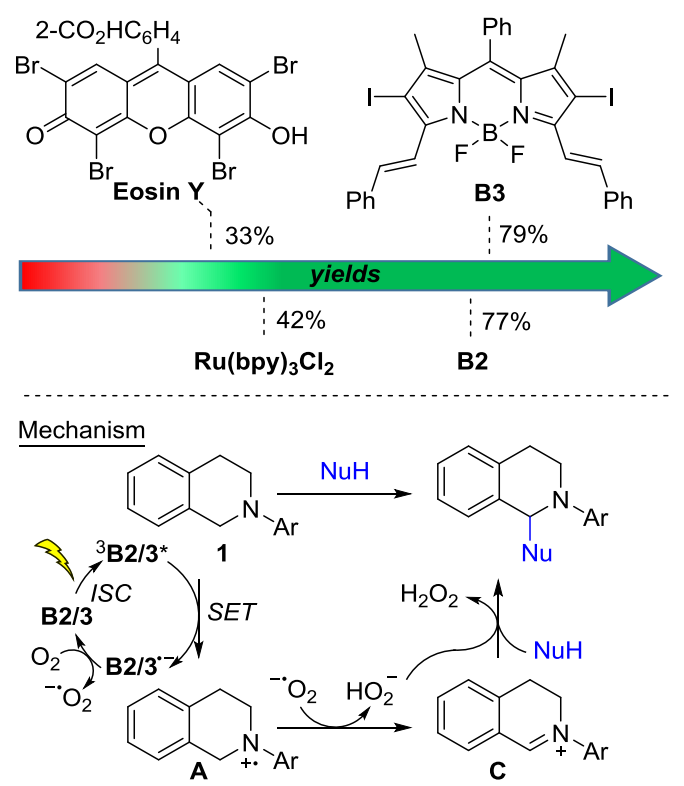

Scheme 3. Reaction of nitroalkanes with $\mathrm{N}$-aryl tetrahydroisoquinolines catalyzed by $\mathbf{B} 2$ or B3.

The proposed mechanism would involve the formation of the radical cation $\mathbf{A}$ via single electron transfer from the starting amine 1 and the excited photocatalyst ${ }^{3}[\mathbf{B} 2 / 3]^{*}$. The reaction of $\mathrm{O}_{2}$ with the radical anion derived from [B2/3] would lead to the superoxide anion radical which would further react with $\mathbf{A}$ to form the iminium species $\mathbf{C}$. The addition of the nitroalkanes to the iminium intermediate $\mathbf{C}$ would produce the compound $\mathbf{3}$.

The iodo-Bodipy dyes B2 and B3 were also applied to the oxidation/[3+2] cycloaddition/aromatization sequence starting 
from tetrahydroisoquinolines 4 (Scheme 4). ${ }^{[29]}$ Using similar catalytic conditions to those employed in Scheme 3, the reaction of $\mathbf{4}$ with $\mathrm{N}$-aryl maleimides $\mathbf{5}$ afforded the products $\mathbf{6}$ in yields ranging from 69 to $91 \%$. As outlined in the previous reaction, Bodipy dyes proved to be superior to the off-the-shelf dyes Eosin $\mathbf{Y}$ and $\mathbf{R u}(\mathrm{bpy})_{3} \mathrm{Cl}_{2}$ for which low levels of yields were obtained. While $\mathrm{N}$-bromosuccinimide (NBS) was required to promote the oxidative dearomatization starting from 4 , the use of tetrahydroisoquinoline bearing a benzoyl group 7 did not lead to the aromatic compound but the polycylic structures $\mathbf{8}$. Addition of NBS led to the decomposition of the products when using 7. A mechanism similar to the previous one was proposed to explain the formation of the products 6 and 8 (See scheme 3). A porous material-immobilized iodo-Bodipy dye has also been successfully employed in the oxidation/[3+2] cycloaddition/aromatization tandem reaction ${ }^{[25]}$ while the groups of Zhao and Li prepared a diiodo-Bodipy postmodified metalorganic framework which was applied to the aerobic reaction of $\mathrm{N}$-aryl tetrahydroisoquinolines $\mathbf{1}$ with nitroalkanes $\mathbf{2}$ and the reaction of tetrahydroisoquinoline 4 with $\mathrm{N}$-aryl and $\mathrm{N}$-benzyl maleimides. ${ }^{[30]}$ For both heterogeneous photocatalysts, recycling studies were carried out without significant decrease of the yields after three reactions.

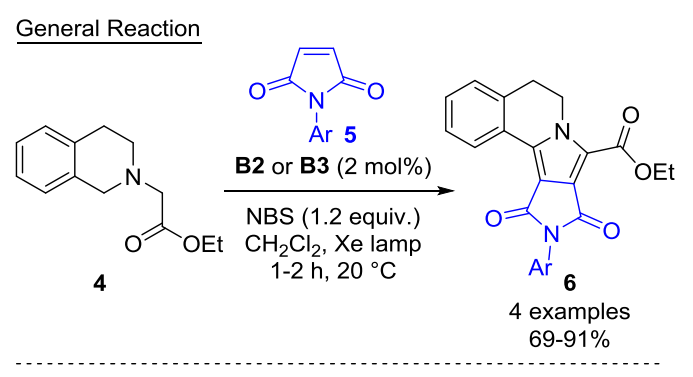

Influence of the photocatalyst (reaction for $\mathrm{Ar}=\mathrm{Ph}, 1 \mathrm{~h}$ )
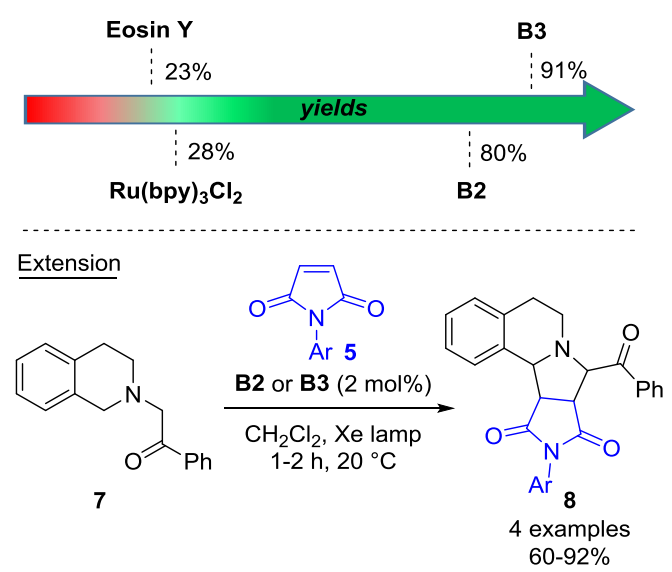

Scheme 4. Multibond forming process towards $\mathbf{6}$ and $\mathbf{8}$ catalyzed by B2 or B3.

The oxidation/[3+2] cycloaddition/aromatization sequence served as a test reaction to investigate new Bodipy-based photocatalysts. Structural evolutions of Bodipy dyes were reported with a special focus on the design of photocatalysts with broad-band visible light absorption (Figure 2). Organic triplet photocatalysts displaying the ability to strongly absorb visible light with a long-lived triplet state are highly sought in photocatalysis. To this aim, a $\mathrm{C}_{60}$ motif was connected to Bodipy chromophores in order to form $\mathrm{C}_{60}$-Bodipy dyad triplet photosensitizers B4 and B5 deprived of heavy atoms which make them appealing dyes in photoredox catalysis owing to the propensity of $\mathrm{C}_{60}$ to be an electron acceptor. ${ }^{[31]}$ These dyads exhibit long-lived triplet states $\left(\tau_{\top}=27.4\right.$ and $71.2 \mu \mathrm{s}$, respectively for $\mathbf{B} 4$ and $\mathbf{B 5}$ ) and strong absorption of visible light. Good-to-excellent levels of yields were obtained in the reaction of tetrahydroisoquinolines $\mathbf{4}$ or $\mathbf{7}$ with $\mathrm{N}$-aryl maleimides $\mathbf{5}$.

In 2014, iodo-aza-Bodipy photocatalysts B6 and B7 have been used in the [3+2] cycloaddition-aromatization tandem reaction between tetrahydroisoquinolines and $\mathrm{N}$-substituted maleimides (Figure 2). ${ }^{[32]}$ The aim of this study was to improve the visible light-harvesting efficiency of the photocatalysts which is of interest for synthetic transformations promoted under broadband light source. lodo-aza-Bodipy frameworks were selected as the core structure of the photocatalysts owing to their much greater red-shifted absorption compared to the Bodipy counterparts. ${ }^{[33]}$ Beside the iodo-aza-Bodipy dye $\mathbf{B 6}$, the authors prepared and characterized the Bodipy-aza-Bodipy triad B7 in which resonance energy transfer was established enabling broadband absorption. ${ }^{[34]}$ Photophysical analyses showed that the fluorescent emission band of Bodipy units attached to the iodoaza-Bodipy framework was quenched in B7 confirming an important energy transfer between these two parts. The two photocatalysts were efficiently applied to the oxidation and $[3+2]$ cycloaddition-aromatization process leading to the desired targets in good yields. It is worthwhile mentioning that better yields were obtained with $\mathbf{B} 7$ and this could be explained by its higher light-harvesting ability.

In the same vein, triplet photosensitizers B8 and B9 incorporating a rhodamine unit as an intramolecular energy donor and an iodo-styryl-Bodipy framework used as an energy acceptor/spin convertor were prepared and tested in the oxidation/[3+2] cycloaddition/aromatization with tetrahydroisoquinolines $\mathbf{4}$ and $\mathrm{N}$-aryl maleimide derivatives $\mathbf{5}$ under the conditions described in Scheme $4 .{ }^{[35]}$ Rhodamine was chosen as a visible light harvesting donor due to its strong absorption in the visible region but at different wavelengths from the Bodipy unit which makes this assembly suitable for application in photocatalysis under panchromatic light. As with B7, photophysical analyses showed an intramolecular energy transfer from the singlet excited state of rhodamine to the styryl Bodipy unit in B8 and B9 and displayed a strong broad-band absorption in the visible region ranging from $450 \mathrm{~nm}$ to $700 \mathrm{~nm}$ for both photocatalysts. These dyes were successfully applied to the formation of $\mathbf{6}$ with moderate to excellent yields.

Another interesting application of iodo-Bodipy dyes in synthetic chemistry is the arylation of furans and thiophenes with aryl diazonium salts (Scheme 5). In previous examples, Bodipy-dyes acted as electron acceptors leading to the oxidation of the substrates. In 2013, the research group of Zhao demonstrated that the excited state of catalysts B2 and B3 could also be used as electron donor in the $\mathrm{C}-\mathrm{H}$ arylation of heteroarenes with aryl diazonium salts. ${ }^{[36]}$ Better yields of $\mathbf{1 0}(\mathrm{X}=\mathrm{O}, \mathrm{R}=\mathrm{H})$ were obtained with B2 and B3 than off-the-shelf photocatalysts Eosin $\mathrm{Y}$ and 


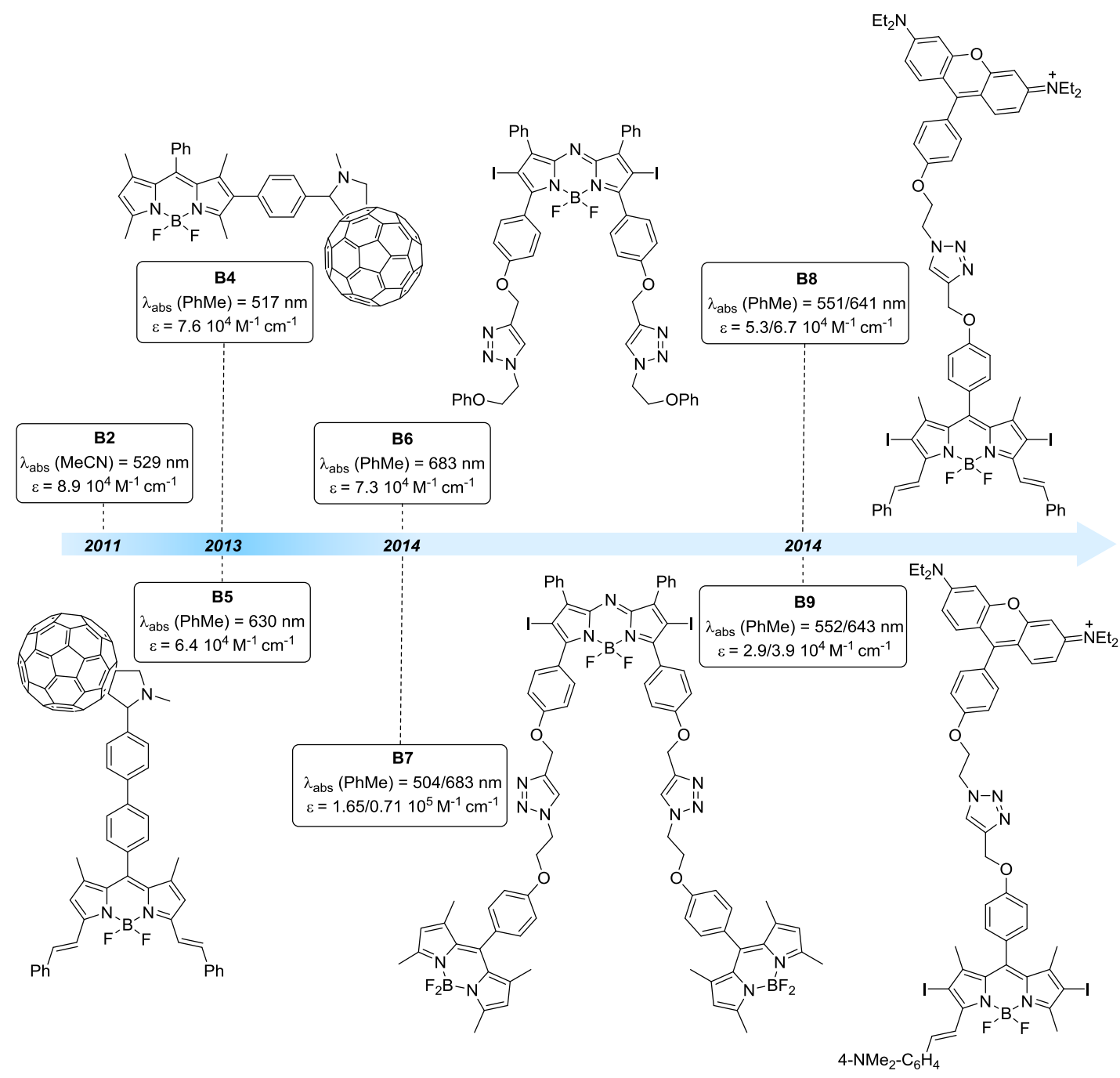

Figure 2. Structural evolution of Bodipy-based photocatalysts with applications in the oxidation/[3+2] cycloaddition/aromatization sequence.

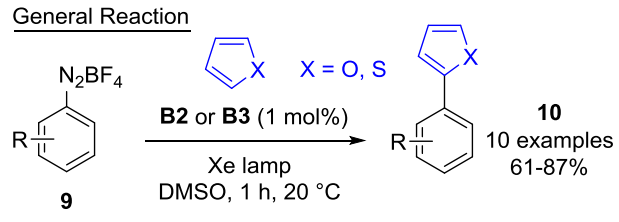

Influence of the photocatalyst (reaction for $\mathrm{X}=\mathrm{O}, \mathrm{R}=\mathrm{H}$ )

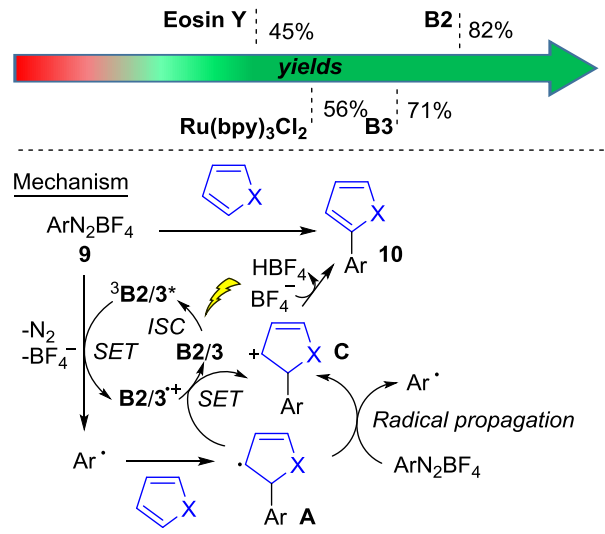

Scheme 5. Photocatalyzed arylation of furans and thiophenes.
$\mathbf{R u}(\mathbf{b p y})_{3} \mathrm{Cl}_{2}$. The substrate scope was studied with a series of aryl diazonium salts and heterocycles (furan, thiophene) and the reaction proved to be general since good-to-excellent yields were obtained in all examples. The proposed mechanism would start with the formation of the aryl radical via single electron transfer which would further react with the heteroarene leading to the radical intermediate $\mathbf{A}$. Oxidation of $\mathbf{A}$ into the cation $\mathbf{C}$ by the radical cation of $\mathbf{B 2} / \mathbf{3}$ followed by deprotonation would lead to the products 10 . Another pathway would involve the oxidation of $\mathbf{A}$ in the presence of the aryl diazonium salt. More recently, Vairaprakash developed a 5-hydroxymethylfurfural-derived Bodipy immobilized on resin support as a catalyst for the arylation of (hetero)arenes with aryl diazonium salts (Figure 3). ${ }^{[37]}$

The dibromo-Bodipy framework was prepared from the raw material 5-hydroxymethylfurfural (HMF) derived from fructose and the dye was immobilized on a polymeric resin. In this report, the catalyst B10 enabled the arylation of furan, thiophene and benzene with diversely substituted aryl diazonium salts under green light irradiation. The recyclability of the immobilized dye B10 was explored and the authors demonstrated that no decrease of the yield was observed after four cycles. 


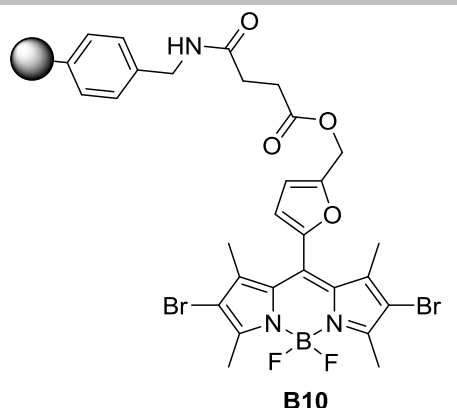

Figure 3. Resin-supported Bodipy B10 derived from 5-hydroxymethylfurfural.

Alkynes are another class of reagents used in Bodipy-catalyzed photoredox transformations as exemplified in Scheme 6. ${ }^{[32]}$

General Reaction

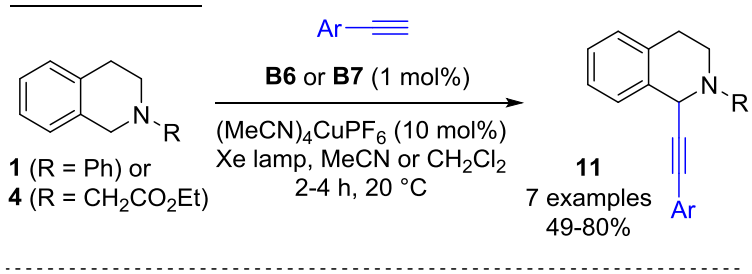

Influence of the photocatalyst (reaction for $\mathrm{R}=\mathrm{Ph}, \mathrm{Ar}=\mathrm{Ph}$ )

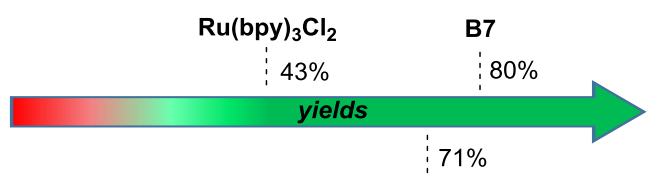

B6

Scheme 6. Merging Copper catalysis and photocatalytic oxidation.

Studies of the copper-catalyzed alkynylation with $\mathrm{N}$-phenyl tetrahydroisoquinoline $\mathbf{1}$ revealed that iodo-aza-Bodipy $\mathbf{B} 6$ and B7 were better catalysts than $\mathbf{R u}(\mathbf{b p y})_{3} \mathbf{C l}_{2}$ exhibiting weak absorption of visible light (See Figure 2 for the molecular structures of B6 and B7). The scope featured aryl acetylenes bearing neutral, electron-donating or electron-withdrawing groups and $\mathrm{N}$-functionalized tetrahydroisoquinolines $\mathbf{1}$ or $\mathbf{4}$. The coupling products 11 were obtained in $49-80 \%$ yields after a short reaction time.

In 2017, the research groups of Ceroni and Cozzi presented a photocatalytic atom-transfer radical addition (ATRA) between bromo derivatives and alkenes promoted by iodo-Bodipy catalyst B2 and sodium ascorbate (Scheme 7). ${ }^{[38]}$ The reaction mechanism proposed by the group consists in the photoexcitation of the iodo-Bodipy B2, followed by the formation of the excited triplet state of B2 through inter-system crossing (ISC). This excited species exhibits strong oxidizing properties and a radical anion is obtained by reaction with ascorbate as a sacrificial reductant. The radical anion then acts as a reductant towards the halogenoalkane, leading to the free radical $\mathbf{A}$ directly involved in the alkene addition. The authors first developed the reaction using the formation of compound $\mathbf{1 4 a}$, leading to the optimized conditions presented in Scheme 7.
General Reaction

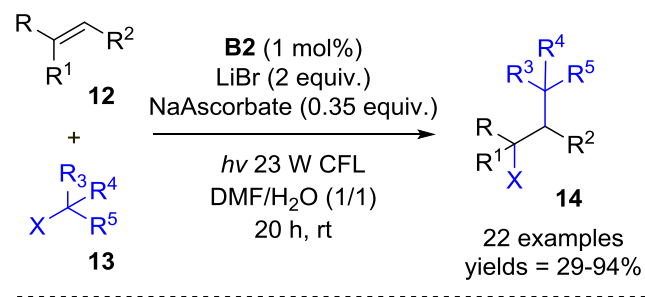

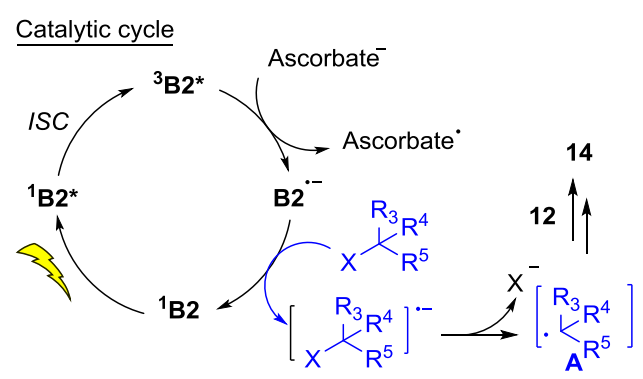

Substrate scope<smiles>CCOC(=O)C(CC(C)CCCCO)C(=O)OCC</smiles>

14a, $94 \% \mathrm{Br}$<smiles>N#CCCC(Br)CCCCO</smiles>

$14 d, 47 \%$<smiles>CCOC(=O)C(C(=O)OCC)C1CCCCCCC1Br</smiles>

Scheme 7. Photocatalytic ATRA reaction.

These conditions were later applied to other alkenes and halogenoalkanes, from which were obtained 22 products. A range of functional groups such as ester, nitrile, pyridinium and alcohol were well tolerated on the organic halides while the alkene scope included terminal and cyclic olefins.

In previous examples, the Bodipy dyes were used as photoredox catalysts promoting $\mathrm{C}-\mathrm{C}$ bond formation through arylation with diazonium salts (Scheme 5). In 2019, Wang, Hao, Jiao and coworkers demonstrated that Bodipy could enable self-promoted radical arylation with diazonium salts (Scheme 8$){ }^{[39]}$ In light of the excited state oxidation potential of $15\left(E_{O X}{ }^{*}=-0.58 \mathrm{~V}\right.$ vs SCE for $\left.\mathrm{R}=2,6-\mathrm{Cl}_{2} \mathrm{C}_{6} \mathrm{H}_{3}\right)$, aryl diazonium salts $\left(E_{\text {red }}=-0.15\right.$ to $\left.-0.5 \mathrm{~V}\right)$ are prone to be reduced by Bodipy under visible light. Optimization of the reaction conditions showed that monoarylated products $\mathbf{1 6}$ were obtained starting from 1.2 equiv. of aryl diazonium salts. Increasing the amount of aryl diazonium salts and the light intensity enabled the selective arylation of $\mathbf{1 5}$ at the 3,5-positions leading to the bis-arylated products 17 . In terms of substrate scope, aryl diazonium salts bearing electron withdrawing groups gave higher yields than substrates with electron-donating groups. The utility of this strategy was illustrated by the synthesis of the indole-fused Bodipy dye 18 based on a two-step procedure involving the photoinduced $\mathrm{C}-\mathrm{H}$ arylation followed by an intramolecular reductive cyclization. 


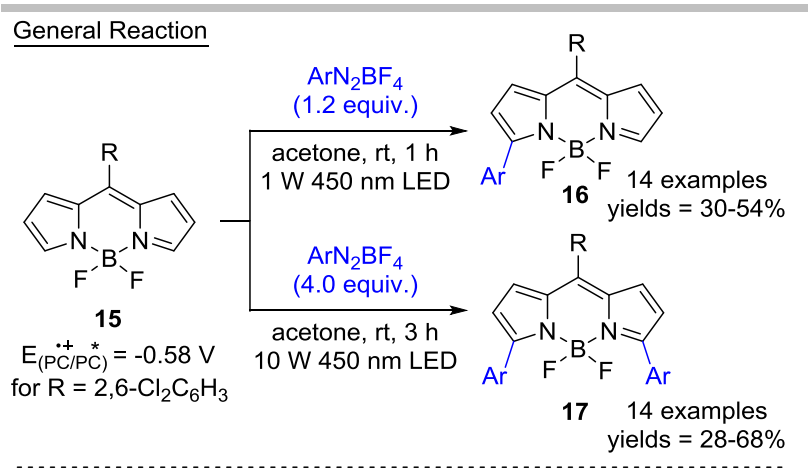

The methodology remains limited to a couple of examples and two $\alpha, \alpha$ - and $\alpha, \gamma$-linked Bodipy dimers were obtained in $28-89 \%$ yields. Similar to the transformation depicted in Scheme 8, the mechanism would involve the excitation of the Bodipy dye which would be then oxidized by photoinduced electron transfer in the presence of silver trifluoroacetate $\left(E_{\text {red }}=0.8 \mathrm{~V}\right)$ to the corresponding radical cation. This species would react with another ground-state molecule of $\mathbf{1 9}$ to give the dimeric products 20 and 21. The same group extended their strategy to the visible light-induced enamination of Bodipy dyes 19 in the presence of secondary and tertiary amines 22 (Scheme 10). ${ }^{[41]}$

\section{$\underline{\text { Mechanism }}$}
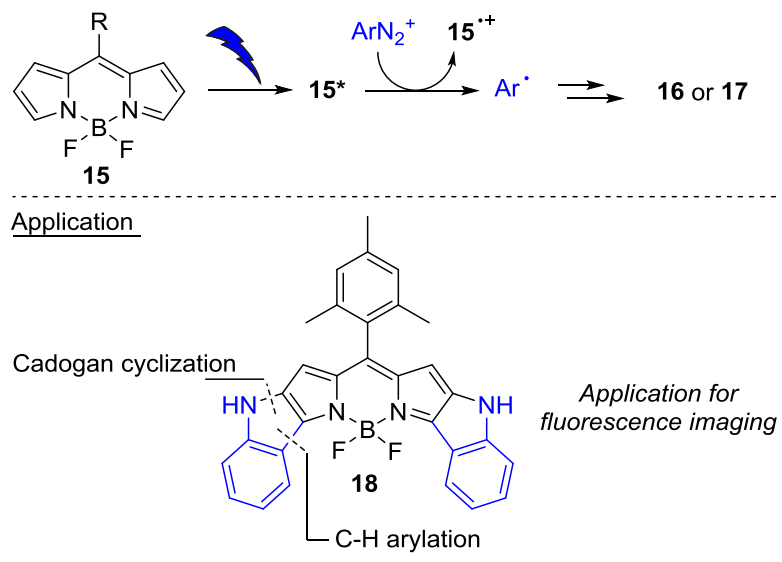

Scheme 8. Visible light induced direct $\mathrm{C}-\mathrm{H}$ arylation of Bodipy dyes

The Bodipy dye 18 exhibited near infrared absorption and bright fluorescence which prompted the researchers to apply this dye to fluorescence imaging in HeLa cells. In 2020, a similar tactic based on the formation of Bodipy-based radical cation was investigated by $\mathrm{HaO}$ and Jiao for promoting the oxidative dimerization of Bodipy dyes 19 under blue LED irradiation (Scheme 9). ${ }^{[40]}$

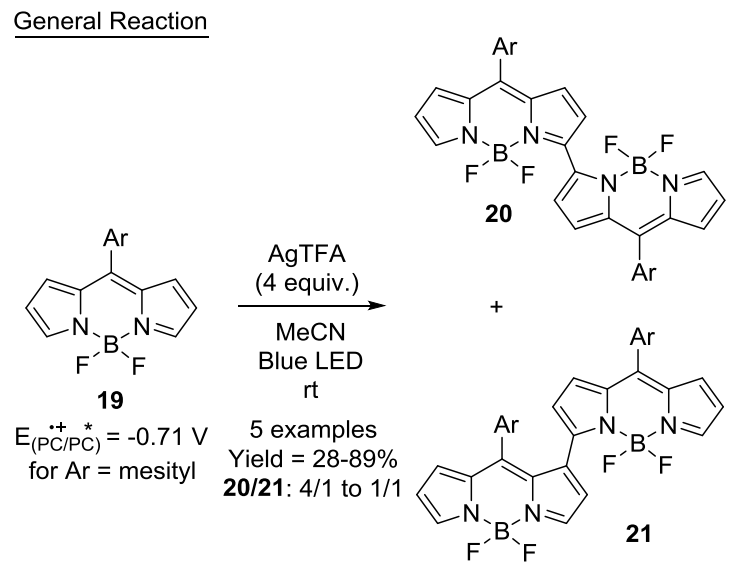

$\underline{\text { Mechanism }}$

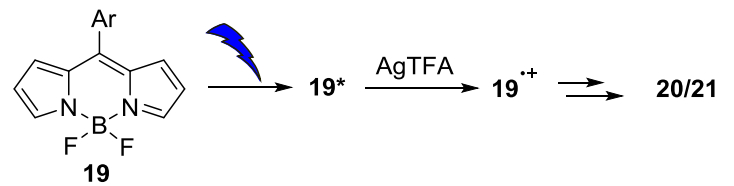

Scheme 9. Oxidative dimerization of Bodipy dyes.

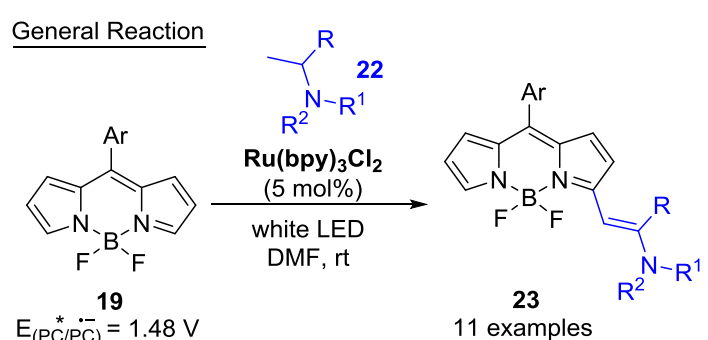

for $\mathrm{Ar}=$ mesityl yields $=20-85 \%$

Simplified mechanism
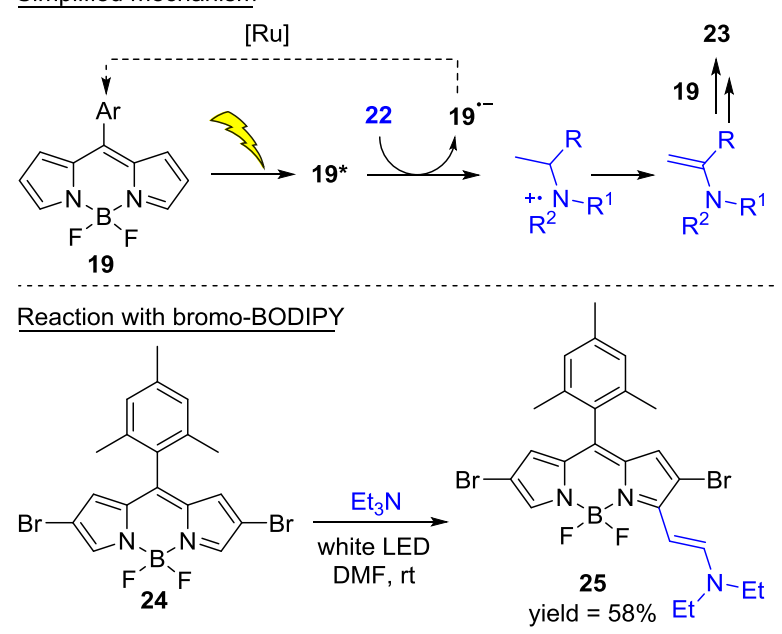

Scheme 10. Enamination of Bodipy dye by photoredox catalysis.

In this example, the photo-oxidizing ability of Bodipy $19\left(E_{\mathrm{red}}{ }^{*}=\right.$ $1.48 \mathrm{~V}$ vs SCE for $\mathrm{Ar}=$ mesityl) has been harnessed for promoting the oxidation of amines 22 into the enamine intermediate. A crucial point for the success of the transformation is the presence of $\mathbf{R u}(\mathbf{b p y})_{3} \mathrm{Cl}_{2}$ which would play the role of triplet photoredox co-catalyst to oxidize the radical anion derived from 19 into the parent neutral Bodipy dye. Interestingly, the functionalization of bromo-Bodipy 24 to form 25 was successfully achieved in the absence of $\mathbf{R u}(\mathbf{b p y})_{3} \mathbf{C l}_{2}$ owing to the propensity of $\mathbf{2 4}$ to act as a triplet photosensitizer under the reaction conditions. Therefore, $\mathbf{R u}(\mathbf{b p y})_{3} \mathrm{Cl}_{2}$ was not required under these reactions conditions. The scope for the enamination of 19 was limited to meso-aryl substituted Bodipy dyes and mixtures of products were obtained starting from diversely substituted tertiary amines such as $\mathrm{N}$-ethyl piperidine, $\mathrm{N}, \mathrm{N}$ dimethylethanamine and $\mathrm{N}, \mathrm{N}$-diisopropyl ethylamine. A secondary amine such as diethylamine was prone to react under these conditions leading to the $\mathrm{NH}$-containing product in a moderate yield.

\subsection{Formation of $\mathrm{C}-\mathrm{O}$ bonds}


The photosensitization of molecular oxygen into singlet oxygen $\left({ }^{1} \mathrm{O}_{2}\right)$ by triplet-triplet energy transfer has been extensively exploited by research groups for carbon-oxygen bond formation. For instance, photooxidation of naphthol derivatives is often used as a benchmark reaction to estimate the propensity of a photocatalyst to produce singlet oxygen. ${ }^{[42]}$ Within this context, the one-pot photooxidation of naphthol $\mathbf{2 6}$ followed by aniline addition to the naphthoquinone intermediate has been described in 2013 using the Bodipy dye B2 as a photocatalyst (Scheme 11) ${ }^{[43]}$

\section{General Reaction}

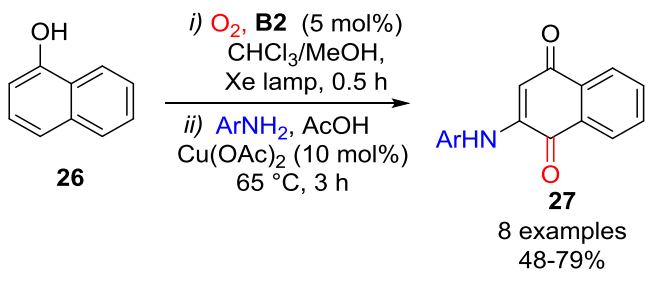

Mechanism

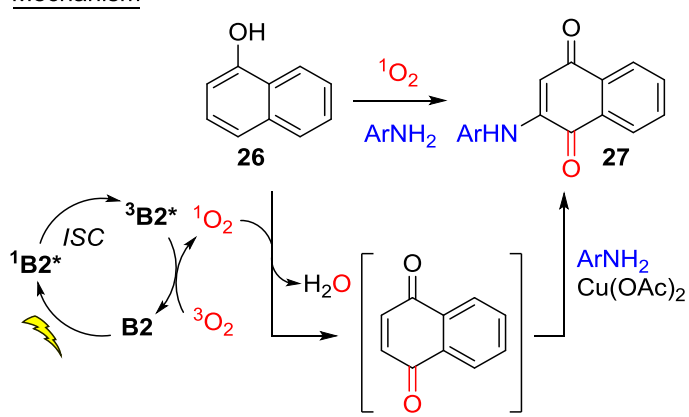

Scheme 11. One-pot formation of aminonaphthoquinones.
After investigating the photooxidation of a focus selection of naphthols into the corresponding quinones, the authors studied the production of aminonaphthoquinones $\mathbf{2 7}$ from naphthol 26 . The one-pot formation of aminonaphthoquinones $\mathbf{2 7}$ started with the photooxygenation of $\mathbf{2 6}$ in the presence of singlet oxygen produced by the iodo-Bodipy dye B2 which is known as an efficient photosensitizer for the production of singlet oxygen. ${ }^{[24]}$ Without isolation of the naphthoquinone intermediate, addition of an aromatic amine, acetic acid and $\mathrm{Cu}(\mathrm{OAc})_{2}$ to the reaction mixture furnished the aminonaphthoquinones $\mathbf{2 7}$ in yields ranging from $48 \%$ to $79 \%$. The scope of naphthol was limited to 1-naphtol 26 while a small set of anilines was tested in the reaction including bromoaniline, chloroaniline and anisidine.

The photooxidation of naphthol $\mathbf{2 6}$ was expanded by Coeffard, Greck and coll. to include a one-pot enantioselective synthesis of 1,4-naphthoquinone-derived polycycles through singlet oxygen-mediated oxidation of naphthol and aminocatalysis (Scheme 12). ${ }^{[4]}$ In the presence of oxygen and a catalytic amount of Bodipy dye B2, naphthol $\mathbf{2 6}$ was oxidized to naphthoquinone under visible light illumination. Addition of dienal 28 (or 29) and the catalytic system (30/Benzoic acid) allowed the formation of $\mathbf{3 1}$ (or 32) with excellent enantioselectivities through a one-pot photooxygenation/trienamine-mediated Diels-Alder/aldol reaction. Besides naphthol derivatives, phenols are an interesting class of compounds to investigate oxidative dearomatization processes. ${ }^{[4]}$ Within this context, the research group of Coeffard has described in 2018 a one-pot synthesis of functionalized fused furans $\mathbf{3 4}$ via a Bodipy-catalyzed domino photooxygenation

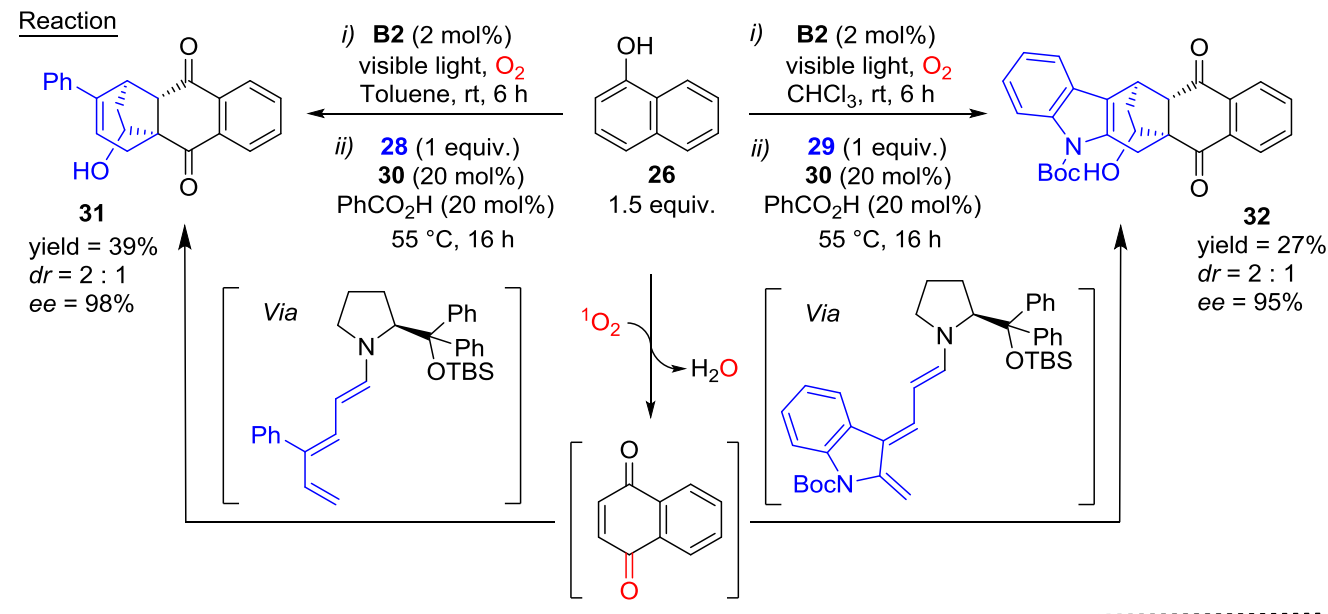

\section{Substrates and catalysts}<smiles>C/C=C(\C=C\C=O)c1ccccc1</smiles>

12.<smiles>Cc1c(/C=C/C=O)c2ccccc2n1C(=O)O</smiles>

enantioselective<smiles></smiles>

30<smiles>CB1n2c(C)c(C)c(C)c2C(c2ccccc2)=C2c3c(C)c(I)c(C)n3B(F)[B-]12F</smiles>

B2 


\section{General Reaction}

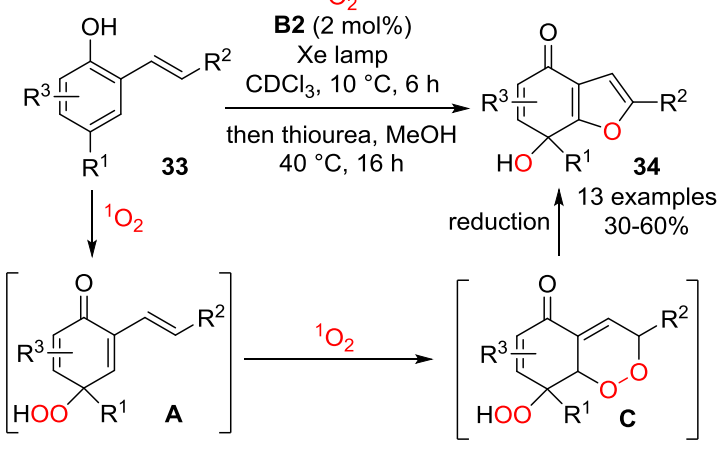

Influence of the photocatalyst $\left(\mathrm{R}^{1}=\mathrm{Me}, \mathrm{R}^{2}=\mathrm{Ph}, \mathrm{R}^{3}=\mathrm{H}\right)$

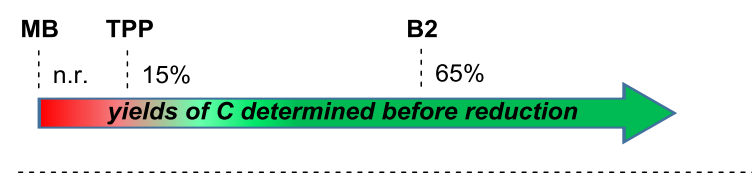

\section{Substrate scope}<smiles>CCCc1cc2c(o1)C(C)(O)C=CC2=O</smiles><smiles>C[14CH2]c1cc2c(o1)C(C)(O)C=CC2=O</smiles>

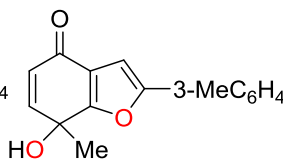

34a, $53 \%$ 34b, $50 \%$ $34 \mathrm{c}, 41 \%$

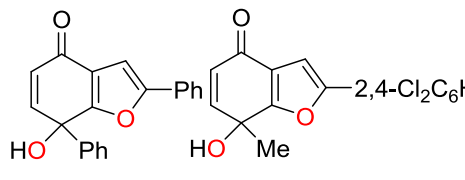

$34 d, 35 \%$

$34 \mathrm{e}, 54 \%$<smiles>CC1=CC(=O)c2cc(-c3ccccc3)oc2C(C)(O)C1</smiles>

34f, $60 \%$

Scheme 13. One-pot synthesis of functionalized fused furans through domino photooxygenation.

Starting from readily available phenols $\mathbf{3 3}$, the first step involves a singlet oxygen mediated dearomatization of the phenol framework leading to the hydroperoxide $\mathbf{A}$. Once generated, the diene system would undergo a [4+2] Diels-Alder reaction with singlet oxygen to form $\mathbf{C}$ which can be further reduced to the fused furans 34. Using a model reaction, optimization of the reaction conditions showed that the Bodipy dye $\mathbf{B 2}$ was the best photocatalyst. The use of methylene blue (MB) or tetraphenylporphyrin (TPP) led to disappointing results. While the scope is quite limited for the substituents $\left(R^{1}, R^{3}\right)$ attached to the phenol ring, this transformation enables the synthesis of functionalized fused furans $\mathbf{3 4}$ using smooth conditions starting from easily accessible phenol derivatives $\mathbf{3 3}$.

In previous examples, phenols and derivatives were used as substrates but these compounds have also been produced through Bodipy dye-mediated photoredox transformations. In 2013, the group of Zhao described the use of Bodipy-based $C_{60}$ dyads and triads for the aerobic oxidation of boronic acids (Scheme 14). ${ }^{[4]}$ For instance, the Bodipy- $\mathrm{C}_{60}$ B5 dyad has been successfully applied in the reaction of tetrahydroisoquinolines 4 or $\mathbf{7}$ with $\mathrm{N}$-aryl maleimides $\mathbf{5}$ owing to its interesting photophysical properties (Scheme 4). Amongst other dyads and triads, the same authors discovered that Bodipy dye B5 smoothly promoted the photooxidation of boronic acids $\mathbf{3 5}$ into phenols 36 .
General Reaction
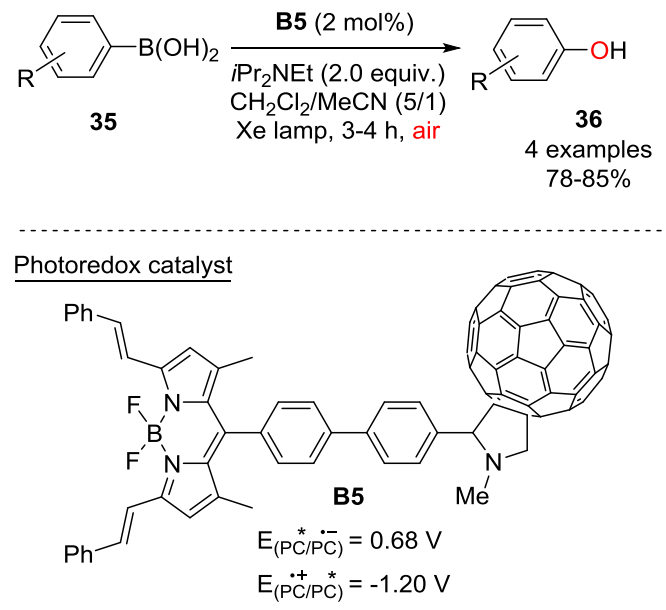

Mechanism

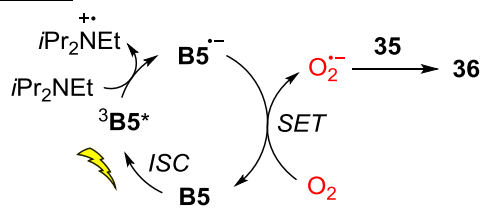

Scheme 14. Aerobic oxidation of boronic acids to phenols.

The reaction scope was limited to a focus selection of boronic acid derivatives $\mathbf{3 5}$ and good yield levels were obtained in short reaction times compared to other organic triplet photosensitizers. Mechanistic studies were carried out highlighting the key role of superoxide radical anion in the photochemical process.

Merging photoredox catalysis and transition metal catalysis has recently delivered groundbreaking results in synthetic chemistry. ${ }^{[48]}$ In 2018, this strategy was applied by the group of Xue to the organophotoredox-nickel catalyzed hydroxylation of aryl halides with water under visible light (Scheme 15) ${ }^{\left[{ }^{[9]}\right.}$ An impressive library of aryl and heteroaryl halides was prone to react with water in the presence of a nickel catalyst and the Bodipy dye B11. The ligand 6,6'-diamino-2,2'-bipyridyl L plays a crucial role in the success of the reaction thanks to the ability of the amino group to interact with water as hydrogen bond acceptor and base. Intensive screening of the reaction conditions showed the striking influence of the Bodipy dye B11 on the yield. A large range of metal-containing and organic photoredox catalysts such as methylene blue (MB), tetraphenylporphyrin (TPP) and rose bengal (RB) were screened and the best result was obtained with $\mathbf{B 1 1}$ for which the higher activity was unclear for the authors. Besides (hetero)aryl bromides, the reaction scope was expanded to more challenging aryl chlorides for which an increase of the temperature was required to reach good levels of yields. From a mechanistic point of view, the transformation would start by insertion of the nickel $(0)$ species into the $\mathrm{C}-\mathrm{X}$ bond and further coordination of water facilitated by the ligand. The excited Bodipy dye B11 ( $E_{\text {red }}{ }^{*}=0.74 \mathrm{~V}$ vs SCE) would oxidize DIPEA which would enable the oxidation of the $\mathrm{Ni}$ " complex into the $\mathrm{Ni}{ }^{11}$ intermediate. Nevertheless, direct oxidation of the $\mathrm{Ni}^{\mathrm{il}}$ species by the excited photocatalyst was not excluded by the authors. Reductive elimination would lead to the formation of the phenol 
products $\mathbf{3 6}$ and the radical anion of $\mathbf{B 1 1}$ would reduce $\mathrm{Ni}^{1}$ to $\mathrm{Ni}^{0}$ to close the catalytic cycle.

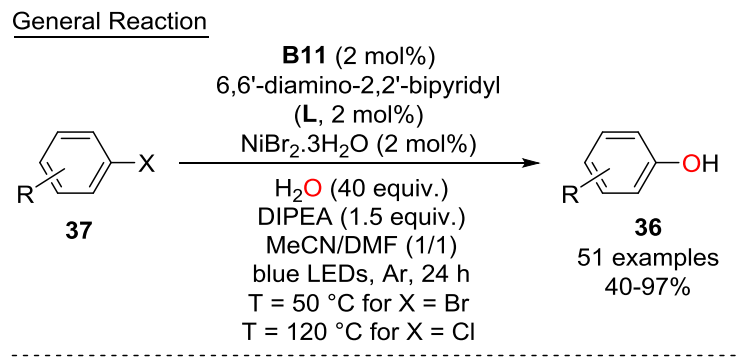

Influence of the photocatalyst (37: 1-bromo-3,5-dimethylbenzene)
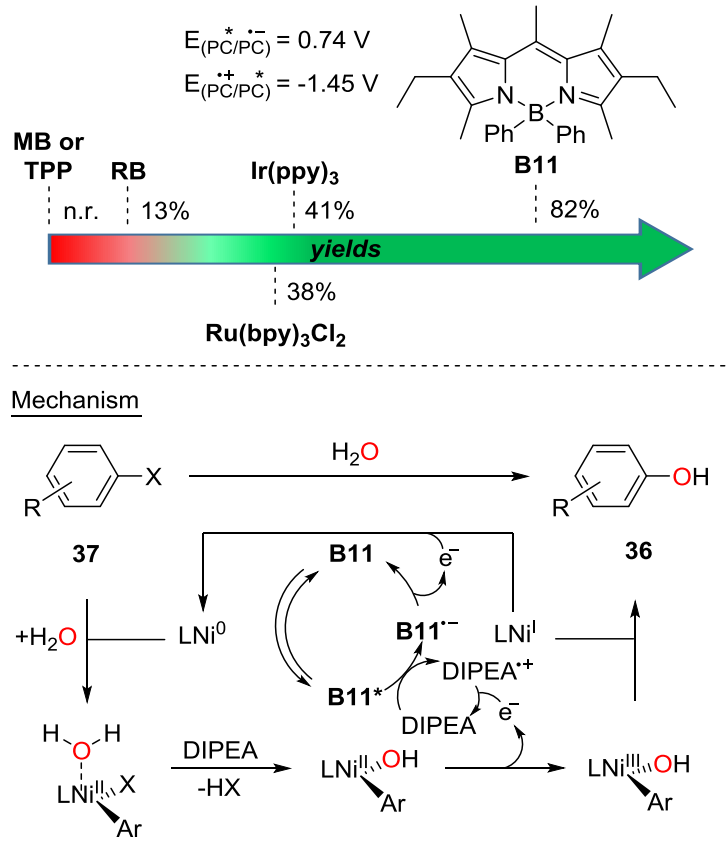

Scheme 15. Photoredox-Nickel dual catalytic hydroxylation of aryl halides with water.

In order to design new catalytic systems for promoting asymmetric photooxygenation, work in our laboratory has been devoted to the design of a quinine-Bodipy photocatalyst for the asymmetric hydroxylation of $\beta$-dicarbonyl compounds 38 (Scheme 16). ${ }^{[50]}$ The Bodipy dye B12 was constructed by connecting a iodo-Bodipy framework known to be an efficient singlet oxygen generator (Scheme 2) and quinine playing both the role of chiral catalyst and singlet oxygen quencher. The bifunctional photocatalyst B12 was applied to a focus selection of indanone- and tetralone-derived $\beta$-keto esters 38 . In spite of a narrow substrate scope and limited enantiomeric excesses, it is a rare example of asymmetric photoinduced transformation involving a Bodipy dye.

\subsection{Formation of S-O bonds}

Sulfoxide is an important structural unit which has found applications in pharmaceutical science and asymmetric catalysis. $^{[51]}$ A practical and selective strategy to produce sulfoxides is the photooxidation of the corresponding sulfides and this transformation is a convenient methodology to determine the oxidizing ability of a photocatalyst. ${ }^{[52]}$ As such, a series of articles compared diversely functionalized Bodipy dyes in the photooxidation of thioanisole $\mathbf{4 0}$ into the corresponding sulfoxide 41 (Scheme 17). ${ }^{[53]}$

\section{General Reaction}

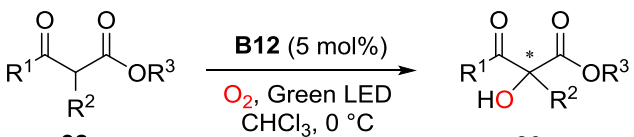

$$
\begin{aligned}
& 38 \quad\left[\text { via }^{1} \mathrm{O}_{2}\right] \quad 39 \\
& 9 \text { examples } \\
& \text { ee of up to } 40 \%
\end{aligned}
$$

Photocatalyst

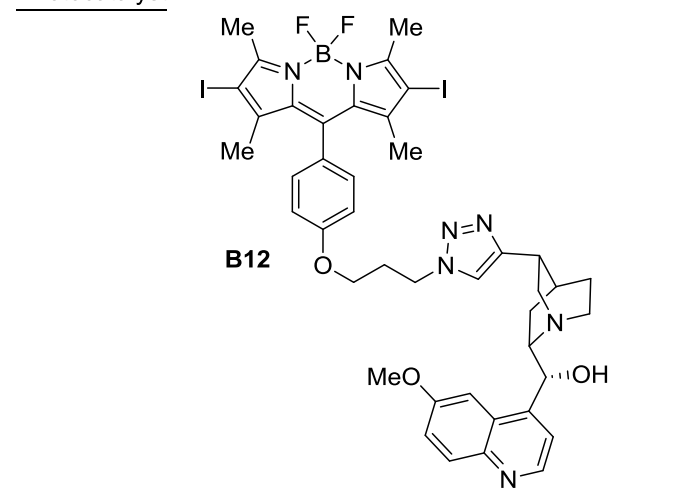

\section{Substrate scope}

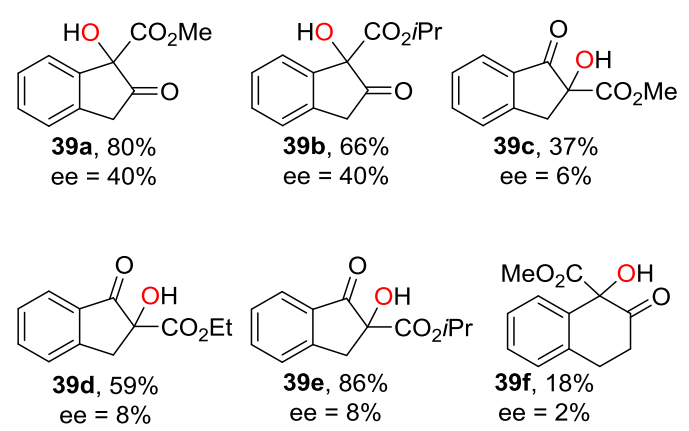

Scheme 16. Asymmetric hydroxylation of $\beta$-dicarbonyl compounds.

The photo-oxidizing ability of Bodipy dyes B1 and B13-B19 deprived of heavy atoms on the Bodipy core were tested against the oxidation of $\mathbf{4 0}$ into $\mathbf{4 1}$ in methanol under visible light. Low yields were obtained by using Bodipy photocatalysts bearing nitro (B14), dimethylamino (B15) and amino (B16) groups on the aromatic side chain. These results could be explained by the competition between singlet oxygen production and a deactivation process like photoinduced electron transfer (PET). The protocol employing B1 and B13-B19 as photocatalysts suffers from long reaction time reaching $24 \mathrm{~h}$ for complete conversion of thioanisole 40 . To tackle this challenge, the authors investigated the iodo-Bodipy dye B2 which exhibits interesting photophysical properties for singlet oxygen generation such as a high molar extinction coefficient and a long-lived triplet excited state (see Scheme 2). A dramatic decrease of the reaction time $(3 \mathrm{~h})$ was observed to reach full conversion of thioanisole 40. Control experiments have also been carried out in order to shed the light on the reactive oxygen species involved in the oxidative process. The authors showed that a Bodipy dye, light and oxygen were required for promoting 
the reaction involving singlet oxygen produced by energy transfer between the excited photocatalyst and ground-state

\section{oxygen.}

Reaction<smiles>CSc1ccccc1</smiles>

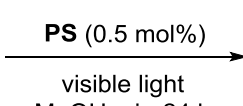
$\mathrm{MeOH}$, air, $24 \mathrm{~h}$

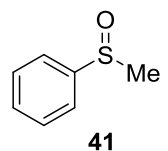

41
Photosensitizers (PS)

B13, $\mathrm{R}=4-\mathrm{MeCONHMeC}_{6} \mathrm{H}_{4}$

B14, $\mathrm{R}=4-\mathrm{NO}_{2} \mathrm{C}_{6} \mathrm{H}_{4}$

B15, $\mathrm{R}=4-\mathrm{NMe}_{2} \mathrm{C}_{6} \mathrm{H}_{4}$

B16, $\mathrm{R}=4-\mathrm{NH}_{2} \mathrm{C}_{6} \mathrm{H}_{4}$

B17, $\mathrm{R}=4-\mathrm{BrC}_{6} \mathrm{H}_{4}$

B18, $\mathrm{R}=4-\mathrm{NPh}_{2} \mathrm{C}_{6} \mathrm{H}_{4}$

B19, $\mathrm{R}=\mathrm{Me}$

B1, $R=P h$

$\mathrm{F}^{-\mathrm{B}_{-}-\mathrm{N}=}$

Influence of the photocatalyst

B1

B1

B2 (3h)

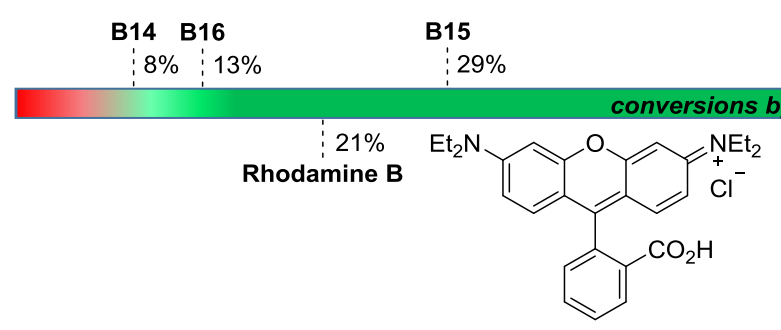

B17.

B19 B18 $\because$ B13

\begin{tabular}{lll:l}
\hline $89 \%$ & $99 \%$ & $100 \%$
\end{tabular}

$98 \%$

$\mathrm{Ru}(\mathrm{bpy})_{3} \mathrm{Cl}_{2}$

Scheme

17.

Photooxidation

of

thioanisole.

With the aim of getting high yields of sulfoxide compounds while not using heavy atom containing photocatalysts, the research group of Cui and He synthesized the Bodipy dye B20 which was applied to the visible light mediated oxidation of sulfides (Scheme 18). ${ }^{[54]}$

\section{General Reaction}

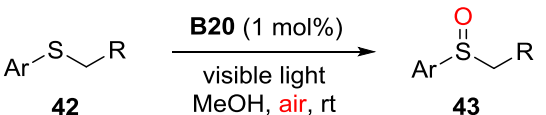

$$
\begin{aligned}
& 6 \text { examples } \\
& \text { Conv. }=82-99 \%
\end{aligned}
$$

Influence of the photocatalyst (42: $\mathrm{Ar}=\mathrm{Ph}, \mathrm{R}=\mathrm{H})$

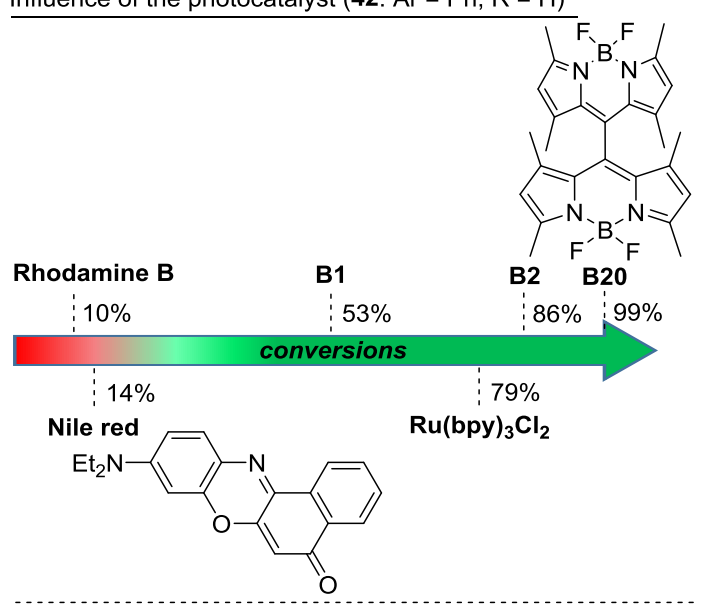

Preparation of $\mathbf{B 2 0}$

$$
\underset{\substack{\text { 2) } \\ \text { yield }=10 \%}}{\stackrel{\text { 1) } 30^{\circ} \mathrm{C}, 2 \mathrm{~h}}{\mathrm{Et}_{2} \mathrm{O} \cdot \mathrm{BF}_{3}}}
$$

Scheme 18. Dimeric Bodipy-catalyzed oxidation of sulfides.
Unlike earlier works describing a lengthy synthetic route towards B20, a straightforward one-step condensation starting from simple oxalyl chloride and 2,4-dimethylpyrrole was described to produce $\mathbf{B 2 0}$ in $10 \%$ yield. After comparing a series of photocatalysts, Cui, $\mathrm{He}$ and coll. demonstrated that the catalyst B20 was competent to oxidize sulfides $\mathbf{4 2}$ into sulfoxides $\mathbf{4 3}$ in the presence of air and visible light irradiation. Nevertheless, the scope was very limited and only conversions determined by NMR were reported lowering the synthetic impact of this study.

\subsection{Miscellaneous}

Previous examples have shown that Bodipy dye B2 is a powerful photocatalyst in synthetic chemistry. In 2013, Zhao and co-workers expanded the utility of $\mathbf{B 2}$ in the oxidation of various amines $\mathbf{4 4}$ into imines $\mathbf{4 5}$ (Scheme 19). ${ }^{[43]}$ The study showed that Bodipy dye B2 is a better catalyst than off-the-shelf organic photocatalysts (TPP, RB) or widely used transition metalcontaining photosensitizers. Moderate-to-excellent conversions were observed for a series of benzyl amine derivatives 44 bearing electron-donating and withdrawing groups even if lower yields were obtained in the latter case. No reaction occurred starting from aniline due to the lack of benzylic hydrogens. The transformation was also performed on gram scale for one example. Mechanistic studies revealed that singlet oxygen would oxidize the amine $\mathbf{4 4}$ into the corresponding imine intermediate which would further react with another molecule of amine 44 to yield the imine 45. In 2016, Xue and coll. reported optimized conditions for the synthesis of amides from aromatic aldehydes and amines under visible light (Scheme 20). ${ }^{[55}$ Various photocatalysts were investigated for the reaction of 4-bromobenzaldehyde with pyrrolidine under blue LED irradiation and the results demonstrated the efficiency of halogen-containing Bodipy dyes B2 and B21. Further optimization revealed the beneficial effect of adding the radical inhibitor BHT (3,5-di-tert-butyl-4-hydroxytoluene) in the reaction mixture. 
General Reaction

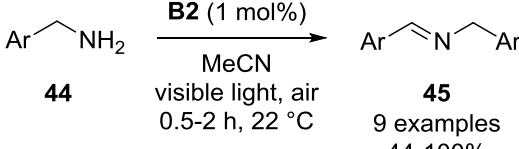

$$
\begin{aligned}
& 44-100 \%
\end{aligned}
$$

Influence of the photocatalyst (reaction for $\mathrm{Ar}=\mathrm{Ph}, 1 \mathrm{~h}$ )
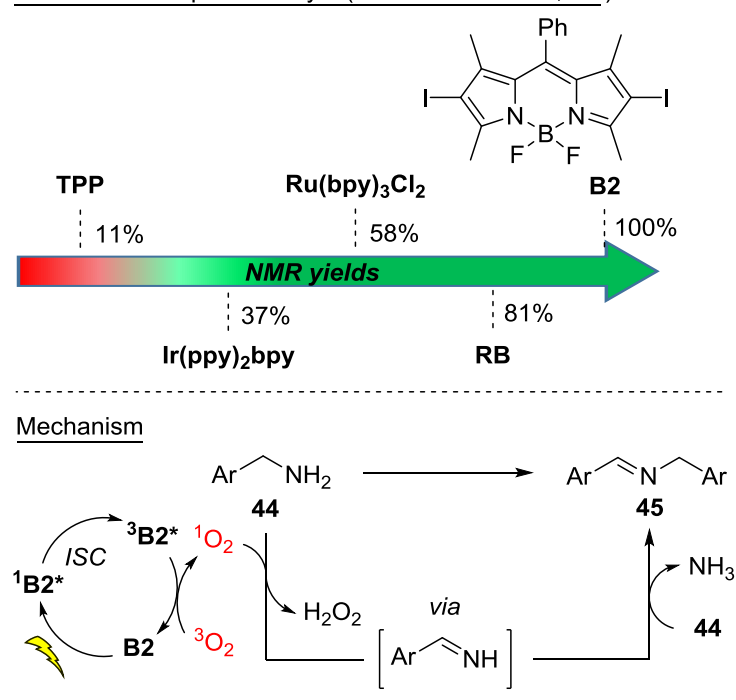

Scheme 19. Oxidation of amines catalyzed by B2.

\section{General Reaction}

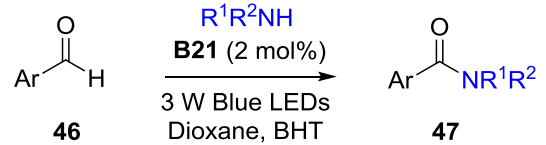

$$
\begin{aligned}
& \text { air, rt } 29 \text { examples } \\
& 35-96 \%
\end{aligned}
$$

Influence of the photocatalyst

Reaction for $\mathrm{Ar}=4-\mathrm{BrC}_{6} \mathrm{H}_{4}$, pyrrolidine, $\mathrm{MeCN}, 12 \mathrm{~h}$

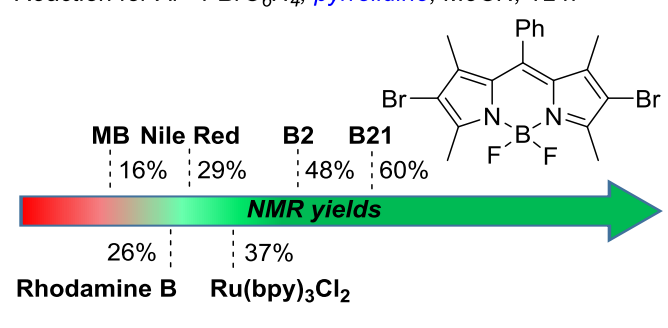

Substrate scope<smiles>O=C(c1ccc(Br)cc1)N1CCCC1</smiles>

47 a, $90 \%$<smiles>O=C(c1cccs1)N1CCCC1</smiles>

47b, $72 \%$<smiles>CN(Cc1ccccc1)C(=O)c1ccc(C#N)cc1</smiles>

47c, $79 \%$ 47e, $0 \%$

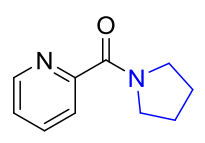<smiles>O=C(c1ccc(Br)cc1)N1CCCCC1</smiles>

47d, $96 \%$
The higher yield could be explained by the ability of BHT-OOH formed in-situ by reaction of BHT with activated oxygen to serve as an oxidant for the amidation between aldehydes and amines. A large panel of aryl and heteroaryl aldehydes and cyclic amines were tested in the oxidative amidation reaction leading to the products $\mathbf{4 7}$ in moderate to excellent yields. Aliphatic aldehydes, as well as primary or aromatic amines were not prone to give the desired products under the reaction conditions.

The landscape of Bodipy-catalyzed transformation is mainly dominated by examples harnessing the triplet excited state of the photosensitizer. In 2015, Meng, Wu and coll. demonstrated that the singlet excited state of Bodipy dye could promote crossdehydrogenative coupling reactions (Scheme 21). ${ }^{[6]}$

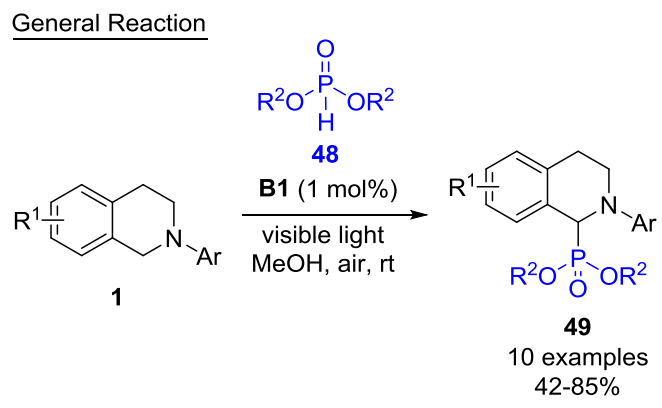

Mechanism

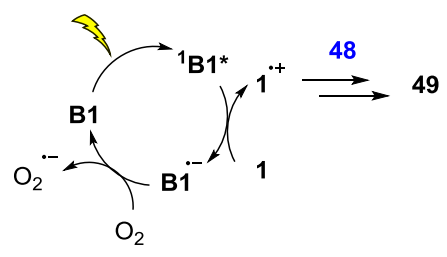

Scheme 21. C-P bond formation.

The authors demonstrated that singlet excited state of fluorescent dye B1 was able to interact with $\mathrm{N}$-aryl tetrahydroisoquinoline $\mathbf{1}$ under visible light leading to a cascade of electron transfer processes. In addition to typical C-C bond formation such as reaction of $\mathbf{1}$ with nitroalkanes or dialkyl malonates, the formation of C-P bond was investigated under photoredox catalysis. Good-to-high levels of yields of $\mathbf{4 9}$ were obtained by reacting $\mathrm{N}$-aryl tetrahydroisoquinoline $\mathbf{1}$ with phosphonate derivatives $\mathbf{4 8}$ using 1 mol\% of Bodipy dye B1.

Examples of visible-light induced functionalization of Bodipy dyes were highlighted in the section dedicated to $\mathrm{C}-\mathrm{C}$ bond formation (Schemes 8-10). This strategy was also explored to introduce ArS units on Bodipy frameworks by $\mathrm{Li}$, Xie and coworkers (Scheme 22). ${ }^{[57]}$ The reaction was based on the fact that excited state of Bodipy $\mathbf{1 9}$ could act as an electron acceptor to form the radical anion derived from 19 and the radical cation of $\mathrm{RSH}$. Deprotonation by the amine would lead to the ArS radical which would attack the $\alpha$-positions of Bodipy 19. Thiophenols bearing electron-withdrawing or electron-donating groups were prone to react with 19 leading to the desired compounds in moderate-to-good overall yields. Nevertheless, the reaction rates depends on the substituents flanked on the thiophenol and a better reactivity was observed with halogen-containing thiophenols. 


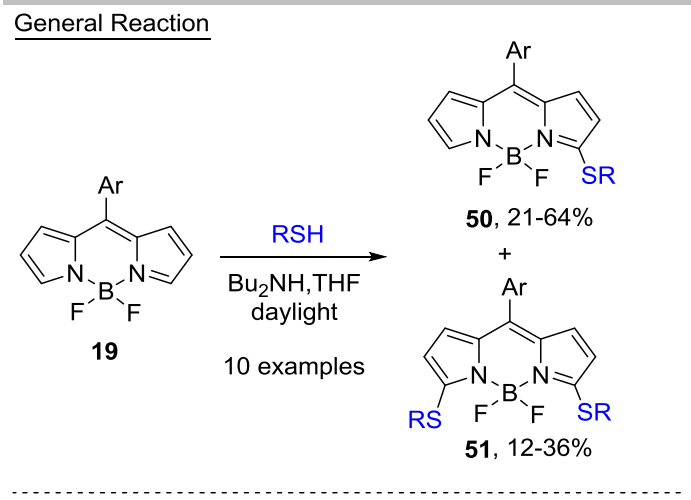

Mechanism

Scheme 22. Introduction of ArS units into the Bodipy core structure.

\section{Metal-tethered Bodipy photocatalysts}

The covalent attachment of a photocatalyst to a transition metal complex is an attractive strategy to discover new reactivities or to improve the catalytic activity of the dual system. ${ }^{[58]}$ In 2019, the research group of $\mathrm{He}$ reported the synthesis of a Bodipyfunctionalized $\mathrm{Pd}(\mathrm{II})$ complex B22 and its application to the visible light-mediated Sonogashira cross-coupling (Scheme 23). ${ }^{[59]}$
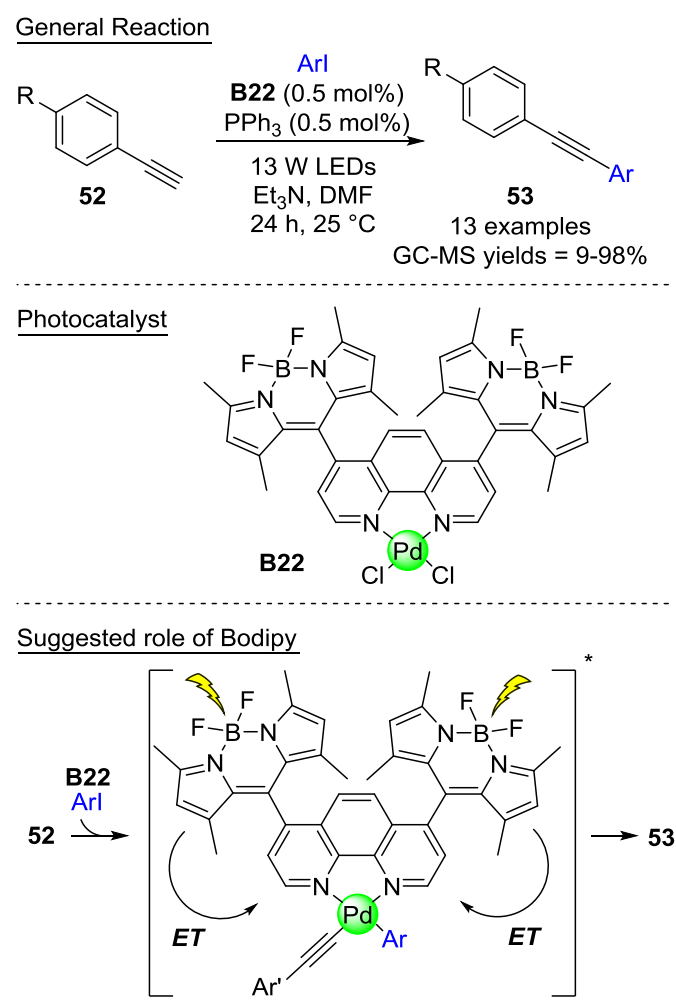

Scheme 23. Sonogashira C-C cross-coupling.
The authors showed that catalyst $\mathbf{B 2 2}$ was able to promote the reaction between iodoarenes and phenylacetylene derivatives under illumination. A very low yield of the reaction between iodobenzene and phenylacetylene was obtained by using only the dichloro(1,10-phenanthroline)palladium(II) compound as a catalyst while the addition of a catalytic amount of Bodipy in the reaction mixture restored the catalytic activity of the system. These data reveal the crucial role of the Bodipy moiety in the reaction outcome. The substrate scope was limited to iodoarenes and phenylacetylene derivatives bearing a substituent at the para position. Low levels of yields were observed with iodoarenes substituted with electron-withdrawing groups $\left(\mathrm{CO}_{2} \mathrm{Et}, \mathrm{CHO}, \mathrm{NO}_{2}\right)$ at para positions. Mechanistic investigations prompted the authors to the conclusion that the reaction proceeds through an energy transfer (ET) mechanism which would facilitate the reductive elimination.

In 2020, Keaveney, Messerle and coll. synthesized a series of tethered dual catalysts based on an $\operatorname{Ir}(\mathrm{I})$ or $\operatorname{Ir}(\mathrm{III})$ complex and a Bodipy photocatalyst (Scheme 24). ${ }^{[60]}$

\section{Photocatalyst}

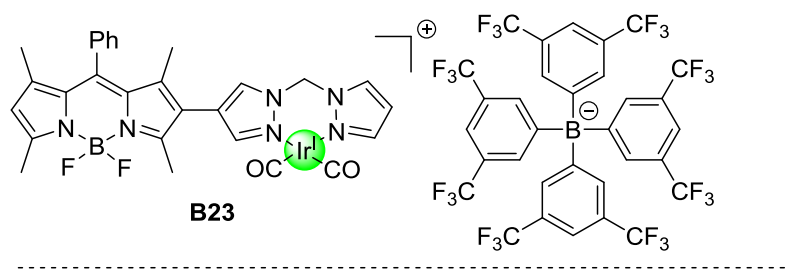

Photocatalytic oxidation

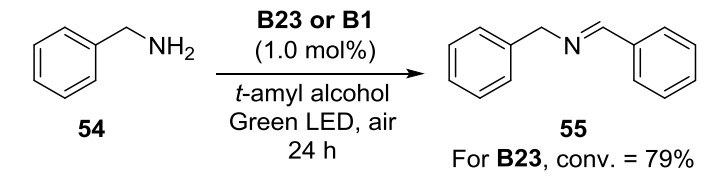

For B1, conv. $=32 \%$

Sequential reactivity

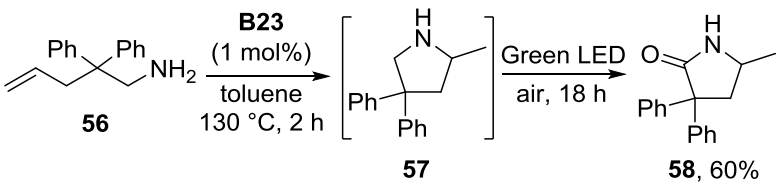

Scheme 24. Bifunctional catalysts featuring an iridium complex and a Bodipy framework.

The bifunctional catalyst B23 was prepared and its catalytic activity was tested against different reactions such as photocatalytic oxidation of benzylamine $\mathbf{5 4}$ and Ir-catalyzed dihydroalkoxylation. Extensive characterization data were provided by the authors which showed a higher singlet oxygen quantum yield for B23 (12.3\% in t-amyl alcohol) than B1 (2.6\%). This result could be explained by the covalent attachment of the $\operatorname{Ir}(\mathrm{I})$ complex to the Bodipy promoting the intersystem crossing. The catalyst B23 was employed in the photocatalytic oxidation of benzylamine $\mathbf{5 4}$ and B23 turned out to be a better catalyst than B1. This could be explained by a higher singlet oxygen quantum yield and the Ir centre could also be involved in the benzylamine oxidation mechanism. The photocatalyst B23 was elegantly applied to the sequential hydroamination-oxidation reaction of $\mathbf{5 6}$ to synthesize the lactam $\mathbf{5 8}$ in $60 \%$ yield over two 
steps. The dual catalyst B23 has also been efficiently used in the photooxidation of thioanisole by the same group. ${ }^{[61]}$

Copper complexes have also been covalently connected to Bodipy chromophores as exemplified by the work of Guo and Zhang on the development of strong visible-light absorbing cuprous photosensitizers such as B24 (Scheme 25). ${ }^{[62]}$

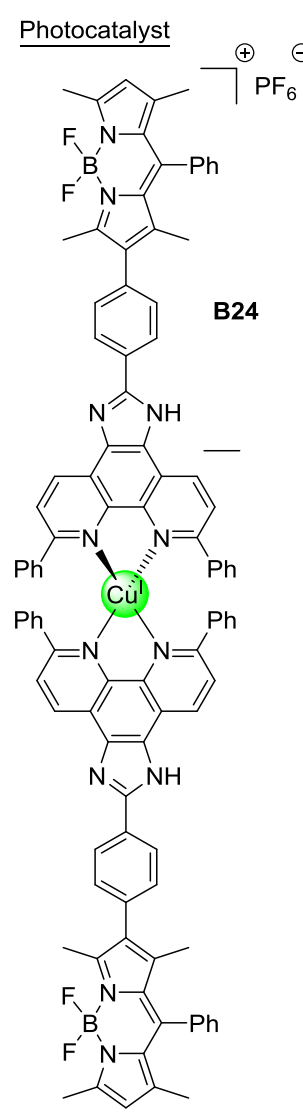

Aerobic oxidation of boronic acids
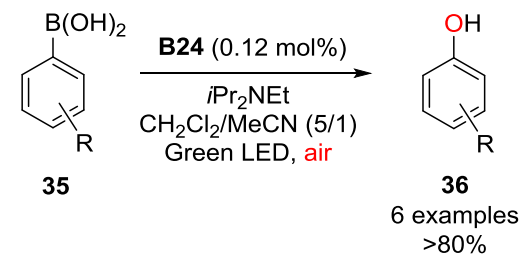

Mechanism

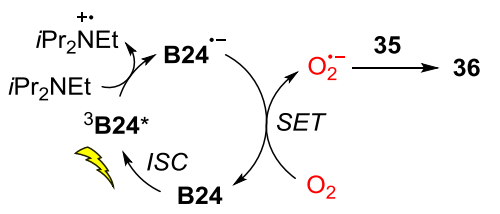

Photooxidation via energy transfer

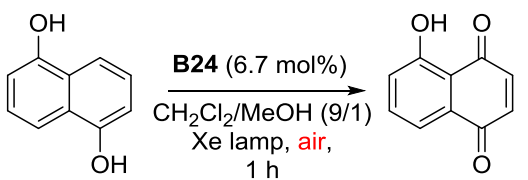

59

via ${ }^{1} \mathrm{O}_{2}$

$60,>80 \%$ was found superior to off-the-shelf photosensitizers such as rose bengal ( $80 \%)$ and tetraphenylporphyrin (62\%).

\section{Summary and Outlook}

The field of synthetic photochemistry has seen major breakthroughs over the past decades. Central to the rapid evolution of this area has been the design of new photocatalytic systems enabling efficient visible light-mediated electron and energy transfer with organic molecules. As showcased in this review, Bodipy dyes occupy a special place in the synthetic photochemistry landscape owing to the chemical and physical features of this class of compounds. In particular, subtle modifications of the Bodipy core structure, such as the introduction of heavy atoms, strongly impact the properties of the photosensitizers paving the way to the preparation of chromophores with efficient triplet state formations. These Bodipy catalysts have found numerous synthetic applications from electron transfer processes to singlet oxygen-mediated transformations. In photoredox transformations, Bodipy dyes have been mainly applied as photooxidants while their uses as electron donors have been limited to a scarce number of transformations such as arylation of heterocycles with diazonium salts. In spite of enormous achievements, it is important to note that energy transfer processes with Bodipy dyes mainly involved the formation of singlet oxygen. Further modulation of the Bodipy core and the level of the triplet excited state is expected to enable the use of these catalysts for other energy transfer processes. In light of the synthetic opportunities offered by the strategies combining photoredox and metal catalysis, the development of Bodipy-metal based structure are promising approaches to uncover new reactivities. Considering the influx of novel catalysts, chiral Bodipy-based catalysts could find exciting opportunities in asymmetric photochemical processes and other research areas.

\section{Acknowledgements}

This work benefited from the support of the project CaROS ANR-18-CE07-0013-01 of the French National Research Agency (ANR). P. D. B. thanks ANR for a Ph.D grant and L. P. thanks the Ministère de l'Enseignement Supérieur, de la Recherche et de I'Innovation for a Ph.D. grant. We also thank Université de Nantes and CNRS for financial support. Dr. Loïc Pantaine is gratefully acknowledged for proofreading this manuscript.

Keywords: Bodipy $•$ Photocatalysis $・$ Visible light $•$ Synthetic methods $\cdot$ Photoredox

[1] According to IUPAC nomenclature, photochemistry is defined as the "change in the rate of a chemical reaction or its initiation under the action of ultraviolet, visible, or infrared radiation in the presence of a substance - the photocatalyst - that absorbs light and is involved in the chemical transformation of the reaction partners." For selected reviews, see: a) T. Rigotti, J. Alemán, Chem. Commun. 2020, 56, 11169-11190 b) C. R. J. Stephenson, T. P. Yoon and D. W. C. MacMillan in Visible Light Photocatalysis in Organic Chemistry, Wiley-VCH, 2018; c) L. Marzo, S. K. Pagire, O. Reiser, B. König, Angew. Chem. 2018, 130 10188-10228; Angew. Chem. Int. Ed. 2018, 57, 10034-10072; d) B. König, Eur. J. Org. Chem. 2017, 1979-1981. 
[2] For selected reviews, see: a) G. E. M. Crisenza, P. Melchiorre, Nat Commun. 2020, 11, 803; b) R. C. McAtee, E. J. McClain, C. R. J. Stephenson, Trends Chem. 2019, 1, 111-125; c) C.-S. Wang, P. H. Dixneuf, J.-F. Soulé, Chem. Rev. 2018, 118, 7532-7585; d) N. A Romero, D. A. Nicewicz, Chem. Rev. 2016, 116, 10075-10166; e) M. H. Shaw, J. Twilton, D. W. C. MacMillan, J. Org. Chem. 2016, 81, 6898-6926; f) T. P. Nicholls, D. Leonori, A. C. Bissember, Nat. Prod. Rep. 2016, 33, 1248-1254.

[3] a) J. Fischer, P. Nun, V. Coeffard, Synthesis 2020, 52, 1617-1624; b) F. Strieth-Kalthoff, F. Glorius, Chem 2020, 6, 1888-1903; c) Q.-Q. Zhou, Y.-Q. Zou, L.-Q. Lu, W.-J. Xiao, Angew. Chem. 2019, 131, 1600-1619 Angew. Chem. Int. Ed. 2019, 58, 1586-1604; d) F. Strieth-Kalthoff, M. J. James, M. Teders, L. Pitzer, F. Glorius, Chem. Soc. Rev. 2018, 47 7190-7202.

[4] G. E. M. Crisenza, D. Mazzarella, P. Melchiorre, J. Am. Chem. Soc 2020, 142, 5461-5476.

[5] a) C. B. Kelly, N. R. Patel, D. N. Primer, M. Jouffroy, J. C. Tellis, G. A. Molander, Nat. Protoc. 2017, 12, 472-492; b) C. K. Prier, D. A. Rankic, D. W. C. MacMillan, Chem. Rev. 2013, 113, 5322-5363.

[6] For selected reviews, see: a) M. Zhong, X. Pannecoucke, P. Jubault, T. Poisson, Beilstein J. Org. Chem. 2020, 16, 451-481; b) A. Hossain, A Bhattacharyya, O. Reiser, Science 2019, 364, eaav9713.

[7] For selected examples, see: a) Y. Zhang, Y. Sun, B. Chen, M. Xu, C. Li, D. Zhang, G. Zhang, Org. Lett. 2020, 22, 1490-1494; b) Y. Li, K. Zhou, Z. Wen, S. Cao, X. Shen, M. Lei, L. Gong, J. Am. Chem. Soc. 2018, 140, 15850-15858; c) Q. M. Kainz, C. D. Matier, A Bartoszewicz, S. L. Zultanski, J. C. Peters, G. C. Fu, Science 2016 $351,681$.

[8] a) M. D. Woodhouse, J. K. McCusker, J. Am. Chem. Soc. 2020, 142, 16229-16233; b) S. Xia, K. Hu, C. Lei, J. Jin, Org. Lett. 2020, 22 , 1385-1389; c) S. Parisien-Collette, A. C. Hernandez-Perez, S. K. Collins, Org. Lett. 2016, 18, 4994-4997; d) A. Gualandi, M. Marchini, L. Mengozzi, M. Natali, M. Lucarini, P. Ceroni, P. G. Cozzi, ACS Catal. 2015, 5, 5927-5931.

[9] a) S. M. Stevenson, R. F. Higgins, M. P. Shores, E. M. Ferreira, Chem. Sci. 2017, 8, 654-660; b) L. A. Büldt, O. S. Wenger, Chem. Sci. 2017 8, 7359-7367; c) R. F. Higgins, S. M. Fatur, S. G. Shepard, S. M. Stevenson, D. J. Boston, E. M. Ferreira, N. H. Damrauer, A. K. Rappé, M. P. Shores, J. Am. Chem. Soc. 2016, 138, 5451-5464; d) M. Stevenson, M. P. Shores, E. M. Ferreira, Angew. Chem. 2015, 127 6606-6610; Angew. Chem. Int. Ed. 2015, 54, 6506-6510.

[10] For selected reviews, see: a) F. Glaser, O. S. Wenger, Coord. Chem. Rev. 2020, 405, 213129; b) B. M. Hockin, C. Li, N. Robertson, E. Zysman-Colman, Catal. Sci. Technol. 2019, 9, 889-915; c) C. B. Larsen, O. S. Wenger, Chem. Eur. J. 2018, 24, 2039-2058; d) N Hoffmann, ChemSusChem 2012, 5, 352-371.

[11] For selected reviews, see : a) Y. Lee, M. S. Kwon, Eur. J. Org. Chem. 2020, 6028-6043; b) M. Uygur, O. García Mancheño, Org. Biomol. Chem. 2019, 17, 5475-5489; c) I. K. Sideri, E. Voutyritsa, C. G. Kokotos, Org. Biomol. Chem. 2018, 16, 4596-4614.

[12] For studies about photostability, see: B. Hinkeldey, A. Schmitt, G. Jung, ChemPhyschem 2008, 9, 2019-2027.

[13] a) N. A. Bumagina, A. Y. Kritskaya, E. V. Antina, M. B. Berezin, A. I. V'yugin, Russ. J. Inorg. Chem. 2018, 63, 1326-1332; b) S. L. Yutanova, M. B. Berezin, A. S. Semeikin, E. V. Antina, G. B. Guseva, A. I. V'yugin, Russ. J. Gen. Chem. 2013, 83, 545-551; c) E. V. Rumyantsev, S. N Alyoshin, Y. S. Marfin, Inorg. Chim. Acta 2013, 408, 181-185; d) L. Yang, R. Simionescu, A. Lough, H. Yan, Dyes Pigm. 2011, 91, 264 267.

[14] M. Wang, M. G. H. Vicente, D. Mason, P. Bobadova-Parvanova, ACS Omega 2018, 3, 5502-5510.

[15] a) J. Zhang, N. Wang, X. Ji, Y. Tao, J. Wang, W. Zhao, Chem. Eur. J. 2020, 26, 4172-4192; b) S. Kolemen, E. U. Akkaya, Coord. Chem. Rev. 2018, 354, 121-134, c) B. Bertrand, K. Passador, C. Goze, F Denat, E. Bodio, M. Salmain, Coord. Chem. Rev. 2018, 358, 108-124 d) E. V. Antina, N. A. Bumagina, A. I. V'yugin, A. V. Solomonov, Dyes Pigm. 2017, 136, 368-381; e) T. Kowada, H. Maeda, K. Kikuchi, Chem. Soc. Rev. 2015, 44, 4953-4972; f) Y. Ni, J. Wu, Org. Biomol. Chem. 2014, 12, 3774-3791; g) N. Boens, V. Leen, W. Dehaen, Chem. Soc. Rev. 2012, 41, 1130-1172; h) R. Ziessel, G. Ulrich, A. Harriman, New J. Chem. 2007, 31, 496-501.
[16] a) R. Prieto-Montero, A. Prieto-Castañeda, R. Sola-Llano, A. R Agarrabeitia, D. García-Fresnadillo, I. López-Arbeloa, A. Villanueva, M. J. Ortiz, S. de la Moya, V. Martínez-Martínez, Photochem. Photobiol. 2020, 96, 458-477; b) W. Sun, X. Zhao, J. Fan, J. Du, X. Peng, Small 2019, 15, 1804927; c) A. M. Durantini, D. A. Heredia, J. E. Durantini, E. N. Durantini, Eur. J. Med. Chem. 2018, 144, 651-661; d) A. Kamkaew, S. H. Lim, H. B. Lee, L. V. Kiew, L. Y. Chung, K. Burgess, Chem. Soc. Rev. 2013, 42, 77-88; e) S. G. Awuah, Y. You, RSC Adv. 2012, 2 11169-11183.

[17] a) M. Poddar, R. Misra, Coord. Chem. Rev. 2020, 421, 213462; b) D. Ho, R. Ozdemir, H. Kim, T. Earmme, H. Usta, C. Kim, ChemPlusChem 2019, 84, 18-37; c) A. Bessette, G. S. Hanan, Chem. Soc. Rev. 2014, 43, 3342-3405.

[18] M. J. Ortiz, I. Garcia-Moreno, A. R. Agarrabeitia, G. Duran-Sampedro, A. Costela, R. Sastre, F. López Arbeloa, J. Bañuelos Prieto, I. López Arbeloa, Phys. Chem. Chem. Phys. 2010, 12, 7804-7811.

[19] A. Treibs, F.-H. Kreuzer, Justus Liebigs Ann. Chem. 1968, 718, 208 223.

[20] For general reviews, see: a) V. Lakshmi, M. Rajeswara Rao, M. Ravikanth, Org. Biomol. Chem. 2015, 13, 2501-2517; b) G. Ulrich, R. Ziessel, A. Harriman, Angew. Chem. 2008, 120, 1202-1219; Angew. Chem. Int. Ed. 2008, 47, 1184-1201.

[21] Z. Li, E. Mintzer, R. Bittman, J. Org. Chem. 2006, 71, 1718-1721.

[22] A. Loudet, K. Burgess, Chem. Rev. 2007, 107, 4891-4932.

[23] a) N. Boens, B. Verbelen, M. J. Ortiz, L. Jiao, W. Dehaen, Coord. Chem. Rev. 2019, 399, 213024; b) N. Boens, B. Verbelen, W. Dehaen, Eur. J. Org. Chem. 2015, 6577-6595.

[24] W. Wu, H. Guo, W. Wu, S. Ji, J. Zhao, J. Org. Chem. 2011, 76, 70567064

[25] For previous syntheses of B1, see: a) Y. Gabe, Y. Urano, K. Kikuchi, H. Kojima, T. Nagano, J. Am. Chem. Soc. 2004, 126, 3357-3367; b) M. Kollmannsberger, K. Rurack, U. Resch-Genger, J. Daub, J. Phys. Chem. A 1998, 102, 10211-10220. For a previous synthesis of B2, see: D. Zhang, Y. Wen, Y. Xiao, G. Yu, Y. Liu, X. Qian, Chem. Commun 2008, 4777-4779.

[26] A. Juris, V. Balzani, P. Belser, A. von Zelewsky, Helv. Chim. Acta 1981 $64,2175-2182$

[27] J. Zhao, K. Xu, W. Yang, Z. Wang, F. Zhong, Chem. Soc. Rev. 2015 44, 8904-8939.

[28] L. Huang, J. Zhao, RSC Adv. 2013, 3, 23377-23388.

[29] S. Guo, H. Zhang, L. Huang, Z. Guo, G. Xiong, J. Zhao, Chem Commun. 2013, 49, 8689-8691.

[30] Y. Quan, Q.-Y. Li, Q. Zhang, W.-Q. Zhang, H. Lu, J.-H. Yu, J. Chen, X. Zhao, X.-J. Wang, RSC Adv. 2016, 6, 23995-23999.

[31] L. Huang, J. Zhao, Chem. Commun. 2013, 49, 3751-3753.

[32] S. Guo, R. Tao, J. Zhao, RSC Adv. 2014, 4, 36131-36139.

[33] Y. Ge, D. F. O'Shea, Chem. Soc. Rev. 2016, 45, 3846-3864

[34] S. Guo, L. Ma, J. Zhao, B. Küçüköz, A. Karatay, M. Hayvali, H. G. Yaglioglu, A. Elmali, Chem. Sci. 2014, 5, 489-500.

[35] J. Ma, X. Yuan, B. Küçüköz, S. Li, C. Zhang, P. Majumdar, A. Karatay, X. Li, H. Gul Yaglioglu, A. Elmali, J. Zhao, M. Hayvali, J. Mater. Chem. C 2014, 2, 3900-3913.

[36] L. Huang, J. Zhao, RSC Adv. 2013, 3, 23377-23388.

[37] R. Rajmohan, P. Nisha, P. Vairaprakash, ACS Omega 2019, 4, 1445814465.

[38] G. Magagnano, A. Gualandi, M. Marchini, L. Mengozzi, P. Ceroni, P. G. Cozzi, Chem. Commun. 2017, 53, 1591-1594.

[39] D. Wang, C. Cheng, Q. Wu, J. Wang, Z. Kang, X. Guo, H. Wu, E. Hao L. Jiao, Org. Lett. 2019, 21, 5121-5125.

[40] D. Wang, Q. Wu, X. Zhang, W. Wang, E. Hao, L. Jiao, Org. Lett. 2020 22, 7694-7698.

[41] D. Wang, X. Guo, H. Wu, Q. Wu, H. Wang, X. Zhang, E. Hao, L. Jiao, J. Org. Chem. 2020, 85, 8360-8370.

[42] a) L. Huang, X. Cui, B. Therrien, J. Zhao, Chem. Eur. J. 2013, 19 17472-17482; b) N. Adarsh, M. Shanmugasundaram, R. R. Avirah, D. Ramaiah, Chem. Eur. J. 2012, 18, 12655-12662

[43] L. Huang, J. Zhao, S. Guo, C. Zhang, J. Ma, J. Org. Chem. 2013, 78 5627-5637

[44] L. Pantaine, V. Coeffard, X. Moreau, C. Greck, Eur. J. Org. Chem. 2015, 2015, 2005-2011. 
[45] For selected reviews, see: a) W.-T. Wu, L. Zhang, S.-L. You, Chem Soc. Rev. 2016, 45, 1570-1580; b) W. Sun, G. Li, L. Hong, R. Wang Org. Biomol. Chem. 2016, 14, 2164-2176.

[46] A. Mauger, J. Farjon, P. Nun, V. Coeffard, Chem. Eur. J. 2018, 24, 4790-4793.

[47] L. Huang, X. Cui, B. Therrien, J. Zhao, Chem. Eur. J. 2013, 19, 17472 17482.

[48] For selected reviews, see: a) L. Guillemard, J. Wencel-Delord, Beilstein J. Org. Chem. 2020, 16, 1754-1804; b) W.-J. Zhou, Y.-H. Zhang, Y.-Y. Gui, L. Sun, D.-G Yu, Synthesis 2018, 50, 3359-3378; c) J. Twilton, C (Chip) Le, P. Zhang, M. H. Shaw, R. W. Evans, D. W. C. MacMillan, Nat. Rev. Chem. 2017, 1, 0052; d) K. L. Skubi, T. R. Blum, T. P. Yoon, Chem. Rev. 2016, 116, 10035-10074.

[49] L. Yang, Z. Huang, G. Li, W. Zhang, R. Cao, C. Wang, J. Xiao, D. Xue, Angew. Chem. 2018, 130, 1986-1990; Angew. Chem. Int. Ed. 2018, 57 1968-1972.

[50] a) J. Fischer, L. Mele, H. Serier-Brault, P. Nun, V. Coeffard, Eur. J. Org. Chem. 2019, 2019, 6352-6358. b) J. Fischer, H. Serier-Brault, P. Nun V. Coeffard, Synlett 2020, 463-468.

[51] J. Han, V. A. Soloshonok, K. D. Klika, J. Drabowicz, A. Wzorek, Chem. Soc. Rev. 2018, 47, 1307-1350.

[52] For examples of sulfide photooxidation by Bodipy-based PS, see: a) A Atilgan, T. Islamoglu, A. J. Howarth, J. T. Hupp, O. K. Farha, ACS Appl. Mater. Interfaces 2017, 9, 24555-24560; b) S. Bandyopadhyay, A. G. Anil, A. James, A. Patra, ACS Appl. Mater. Interfaces 2016, 8, 2766927678; c) M. Liras, M. Iglesias, F. Sánchez, Macromolecules 2016, 49 1666-1673; d) W. Li, W. Zhang, X. Dong, L. Yan, R. Qi, W. Wang, Z. Xie, X. Jing, J. Mater. Chem. 2012, 22, 17445-17448.

[53] a) L. Quan, W. Lin, T. Sun, Z. Xie, Y. Huang, X. Jing, Catal. Lett. 2014 144, 308-313; b) W. Li, L. Li, H. Xiao, R. Qi, Y. Huang, Z. Xie, X. Jing, H. Zhang, RSC Adv. 2013, 3, 13417-13421; c) W. Li, Z. Xie, X. Jing, Catal. Commun. 2011, 16, 94-97.

[54] L. Wang, J. Cao, J. Wang, Q. Chen, A. Cui, M. He, RSC Adv. 2014, 4 14786-14790

[55] X.-F. Wang, S.-S. Yu, C. Wang, D. Xue, J. Xiao, Org. Biomol. Chem. 2016, 14, 7028-7037.

[56] X.-Z. Wang, Q.-Y. Meng, J.-J. Zhong, X.-W. Gao, T. Lei, L.-M. Zhao, Z.J. Li, B. Chen, C.-H. Tung, L.-Z. Wu, Chem. Commun. 2015, 51 11256-11259.

[57] F. Ma, L. Zhou, Q. Liu, C. Li, Y. Xie, Org. Lett. 2019, 21, 733-736.

[58] X. Lang, J. Zhao, X. Chen, Chem. Soc. Rev. 2016, 45, 3026-3038.

[59] K. C. Dissanayake, P. O. Ebukuyo, Y. J. Dhahir, K. Wheeler, H. He, Chem. Commun. 2019, 55, 4973-4976.

[60] D. Wang, R. Malmberg, I. Pernik, S. K. K. Prasad, M. Roemer, K. Venkatesan, T. W. Schmidt, S. T. Keaveney, B. A. Messerle, Chem. Sci. 2020, 11, 6256-6267.

[61] a) D. Wang, N. S. D. Solomon, I. Pernik, B. A. Messerle, S. T. Keaveney, Aust. J. Chem. 2020, 73, 979-986; b) D. Wang, I. Pernik, S. T. Keaveney, B. A. Messerle, ChemCatchem 2020, 12, 5091-5097.

[62] K.-K. Chen, S. Guo, H. Liu, X. Li, Z.-M. Zhang, T.-B. Lu, Angew. Chem 2020, 132, 13051-13057; Angew. Chem. Int. Ed. 2020, 59, 1295112957. 


\section{Entry for the Table of Contents}

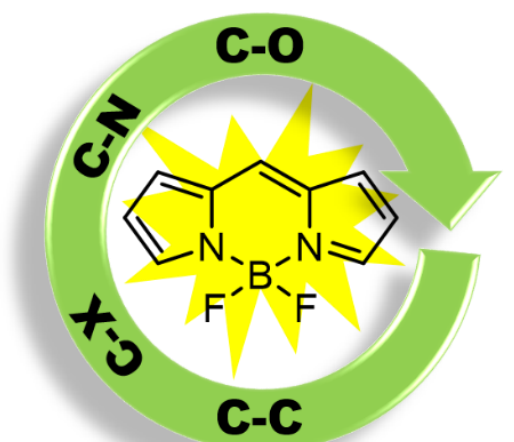

Bodipy (Boron-dipyrromethene) derivatives are important dyes with a variety of applications including functionalized materials, biology, medicine and organic chemistry. This review covers important developments in the use of Bodipy dyes in synthetic photochemistry.

Institute and/or researcher Twitter usernames: Dr. Vincent Coeffard: @CoeffardV•Dr. Pierrick Nun: @pierrick_n・CEISAM institute: @CeisamLab 